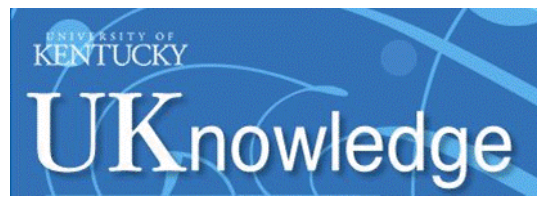

University of Kentucky

UKnowledge

\title{
The Impact of SGLT2 Inhibitors, Compared with Insulin, on Diabetic Bone Disease in a Mouse Model of Type 1 Diabetes
}

\author{
Kathryn M. Thrailkill \\ University of Kentucky, kathryn.thrailkill@uky.edu \\ Jeffry S. Nyman \\ Vanderbilt University \\ R. Clay Bunn \\ University of Kentucky, clay.bunn@uky.edu \\ Sasidhar Uppuganti \\ Vanderbilt University \\ Katherine L. Thompson \\ University of Kentucky, katherine.thompson@uky.edu
}

See next page for additional authors

Follow this and additional works at: https://uknowledge.uky.edu/diabetes_facpub

Part of the Diseases Commons, and the Endocrinology, Diabetes, and Metabolism Commons

Right click to open a feedback form in a new tab to let us know how this document benefits you.

\section{Repository Citation}

Thrailkill, Kathryn M.; Nyman, Jeffry S.; Bunn, R. Clay; Uppuganti, Sasidhar; Thompson, Katherine L.; Lumpkin, Charles K.; Kalaitzoglou, Evangelia; and Fowlkes, John L., "The Impact of SGLT2 Inhibitors, Compared with Insulin, on Diabetic Bone Disease in a Mouse Model of Type 1 Diabetes" (2017). Barnstable Brown Diabetes Center Faculty Publications. 6.

https://uknowledge.uky.edu/diabetes_facpub/6

This Article is brought to you for free and open access by the Diabetes at UKnowledge. It has been accepted for inclusion in Barnstable Brown Diabetes Center Faculty Publications by an authorized administrator of UKnowledge. For more information, please contact UKnowledge@lsv.uky.edu. 


\section{The Impact of SGLT2 Inhibitors, Compared with Insulin, on Diabetic Bone Disease in a Mouse Model of Type 1 Diabetes}

\section{Digital Object Identifier (DOI)}

https://doi.org/10.1016/j.bone.2016.10.026

Notes/Citation Information

Published in Bone, v. 94, p. 141-151.

(c) 2016 Elsevier Inc. All rights reserved.

This manuscript version is made available under the CC-BY-NC-ND 4.0 license https://creativecommons.org/licenses/by-nc-nd/4.0/.

The document available for download is the author's post-peer-review final draft of the article.

Authors

Kathryn M. Thrailkill, Jeffry S. Nyman, R. Clay Bunn, Sasidhar Uppuganti, Katherine L. Thompson, Charles K. Lumpkin, Evangelia Kalaitzoglou, and John L. Fowlkes 
Published in final edited form as:

Bone. 2017 January ; 94: 141-151. doi:10.1016/j.bone.2016.10.026.

\title{
The impact of SGLT2 Inhibitors, compared with Insulin, on Diabetic Bone Disease in a mouse model of Type 1 Diabetes
}

\author{
Kathryn M. Thrailkill, MDa, Jeffry S. Nyman, $\mathrm{PhD}^{\mathrm{b}}$, R. Clay Bunn, $\mathrm{PhD}^{\mathrm{a}}$, Sasidhar \\ Uppuganti, $\mathbf{M S}^{b}$, Katherine L. Thompson, $\mathrm{PhD}^{\mathrm{c}}$, Charles K. Lumpkin Jr., PhD ${ }^{\mathrm{d}}$, Evangelia \\ Kalaitzoglou, MDa , and John L. Fowlkes, MDa \\ aUniversity of Kentucky Barnstable Brown Diabetes Center and the Department of Pediatrics, \\ University of Kentucky College of Medicine, Lexington, KY 40536 \\ bVA Tennessee Valley Health Care System, Department of Orthopaedic Surgery \& Rehabilitation, \\ and Center for Bone Biology, Vanderbilt University Medical Center, Nashville, TN 37232 \\ 'Department of Statistics, University of Kentucky, Lexington, KY 40536 \\ ${ }^{\mathrm{d}}$ Department of Pediatrics, University of Arkansas for Medical Sciences, Little Rock, AR, 72202 \\ USA
}

\section{Abstract}

Skeletal co-morbidities in type 1 diabetes include an increased risk for fracture and delayed fracture healing, which are intertwined with disease duration and the presence of other diabetic complications. As such, chronic hyperglycemia is undoubtedly a major contributor to these outcomes, despite standard insulin-replacement therapy. Therefore, using the streptozotocin (STZ)-induced model of hypoinsulinemic hyperglycemia in DBA/2J male mice, we compared the effects of two glucose lowering therapies on the fracture resistance of bone and markers of bone turnover. Twelve week-old diabetic (DM) mice were treated for 9 weeks with: 1) oral canagliflozin (CANA, dose range $\sim 10-16 \mathrm{mg} / \mathrm{kg} / \mathrm{day}$ ), an inhibitor of the renal sodium-dependent glucose cotransporter type 2 (SGLT2); 2) subcutaneous insulin, via minipump (INS, 0.125 units/day); 3) cotherapy (CANA + INS); or 4) no treatment (STZ, without therapy). These groups were also compared to non-diabetic control groups. Untreated diabetic mice experienced increased bone resorption and significant deficits in cortical and trabecular bone that contributed to structural weakness of the femur mid-shaft and the lumbar vertebra, as determined by three-point bending

Corresponding Author: Kathryn M. Thrailkill, MD, University of Kentucky, UK Barnstable Brown Diabetes Center, 830 S. Limestone St., Lexington, KY 40536, kathryn.thrailkill@uky.edu.

Publisher's Disclaimer: This is a PDF file of an unedited manuscript that has been accepted for publication. As a service to our customers we are providing this early version of the manuscript. The manuscript will undergo copyediting, typesetting, and review of the resulting proof before it is published in its final citable form. Please note that during the production process errors may be discovered which could affect the content, and all legal disclaimers that apply to the journal pertain.

Duality of Interests:

The authors have no financial or personal conflicts of interest to disclose.

Author Contributions:

K.M.T., R.C.B., C.K.L, and J.L.F. contributed to the design of the experiment. K.M.T., R.C.B., J.S.N., S.U., and J.L.F. researched data, contributed to discussion, wrote manuscript and reviewed/edited manuscript. E.K. contributed to the discussion and reviewed/edited the manuscript. C.K.L. monitored and maintained compliance of all animal procedure with the UAMS IACUC. K.L.T. provided statistical analysis and interpretation of the data, wrote the manuscript, and reviewed/edited manuscript. K.M.T and K.L.T. accept responsibility for the integrity of the data analysis. All authors have approved the final version of the submitted manuscript. 
and compression tests, respectively. Treatment with either canagliflozin or insulin alone only partially rectified hyperglycemia and the diabetic bone phenotype. However, when used in combination, normalization of glycemic control was achieved, and a prevention of the DM-related deterioration in bone microarchitecture and bone strength occurred, due to additive effects of canagliflozin and insulin. Nevertheless, CANA-treated mice, whether diabetic or non-diabetic, demonstrated an increase in urinary calcium loss; FGF23 was also increased in CANA-treated DM mice. These findings could herald ongoing bone mineral losses following CANA exposure, suggesting that certain CANA-induced skeletal consequences might detract from therapeutic improvements in glycemic control, as they relate to diabetic bone disease.

\section{Keywords}

Bone microarchitecture; cortical bone; trabecular bone; glycosuria; hypercalciuria; canagliflozin; dapagliflozin

\subsection{INTRODUCTION}

Persons with type 1 or type 2 diabetes (T1D, T2D) have a significantly higher fracture risk than age-matched persons without diabetes. This propensity for fracture, however, is not predicted by bone mineral density (BMD) measurements alone, but instead is attributed to deficits in the microarchitecture and in the material properties of the bone tissue. This condition is now referred to as diabetic bone disease (DBD)(1).

Sodium-dependent glucose co-transporter type 2 (SGLT2) inhibitors (SGLT2Is) are a newer class of drugs which selectively inhibit the renal co-transport (i.e., reuptake) of glucose and sodium within the early proximal convoluted tubule, by blocking the renal SGLT2 cotransporter. By increasing urinary glucose excretion, they are effective in improving glycemic control in persons with type 2 diabetes (T2D), whether as monotherapy $(2,3)$, or as co-therapy, in combination with insulin $(4,5)$ or with a variety of oral hypoglycemic agents (6-9). However, recent studies also suggest that SGLT2Is may be efficacious, as adjunct-to-insulin therapy, in T1D (10), and off-label use of SGLT2Is in T1D is being increasingly reported (11-13). The use of SGLT2 inhibition for the treatment of all diabetes is expected to increase, because of: 1) the unique mechanism of action (increased glycosuria) $(14,15) ; 2)$ the greater durability of effect, compared with other drug classes $(16) ; 3)$ the preferential efficacy in patients with more poorly controlled diabetes $(2,17) ; 4)$ the concurrent beneficial reductions in weight and blood pressure that occur in persons with T2D taking these medications (17); 5) the potential applicability to both T1D and T2D; and 6) the potential to minimize hypoglycemia risk in intensively managed T1D (13).

Early clinical investigations in T2D demonstrated a concerning increase in bone fractures in patients receiving the SGLT2Is, canagliflozin (18) or dapagliflozin (19), with bone fractures occurring as early as 12 weeks after drug initiation (18). This led the US Food and Drug Administration (FDA) to issue additional guidance regarding fracture risk associated with canagliflozin (www.fda.gov/Drugs/DrugSafety/ucm461449.htm). Mechanisms of action of this drug class could contribute to compensatory increases in serum parathyroid hormone in response to drug-induced renal phosphate reabsorption, or to secondary increases in urinary 
calcium excretion, due to the osmotic diuresis of enhanced glycosuria (20). However, such physiological responses could also detrimentally impact skeletal integrity over time, particularly when paired with the already elevated fracture risk of a diabetic population. Currently, very limited data is available on the effects of SGLT2 inhibition on bone mineral homeostasis or bone turnover; and the effects of SGLT2I on skeletal integrity in T1D are largely unknown.

Previously, we have investigated the effects of SGLT2I treatment in a rodent model of streptozotocin (STZ)-induced diabetes (a model of hypoinsulinemic diabetes) for 10 weeks (21), demonstrating that despite a significant improvement in glycemic control with SGLT2I treatment, diabetes-related bone deficits were not alleviated. Such findings raise the possibility that adverse skeletal effects from SGLT2I exposure might be occurring independent of drug-related beneficial metabolic improvements. To address this possibility, we sought to compare the relative impact of bio-equivalent glucose-lowering, achieved either with SGLT2I treatment or with insulin treatment, on diabetic bone disease in a mouse model of hypoinsulinemic diabetes (i.e., T1D). In this way, comparisons could be made regarding the relative contribution of glycemic improvements alone, verses other nonglycemic pharmacological effects of SGLT2I drugs on skeletal outcomes. The objective of this investigation, therefore, was to examine the effects of SGLT2I treatment on bone microarchitecture and bone quality in a model of long-term hypoinsulinemic diabetes (i.e., T1D), as compared with standard insulin-replacement therapy in hypoinsulinemic diabetes.

\subsection{RESEARCH DESIGN AND METHODS}

\subsubsection{Animals and Experimental Design}

Ten-week old male, DBA/2J mice (The Jackson Laboratories, Bar Harbor, ME), a strain prone to the development of diabetic complications (7), were treated either with streptozotocin (STZ) to induce diabetes $(40 \mathrm{mg} / \mathrm{kg} /$ day $\times 5$ days $)$ or with vehicle $(100 \mathrm{mM}$ citrate, $\mathrm{pH} 4.5$ ), by intraperitoneal (i.p.) injection. At $\sim 12$ weeks of age, vehicle-injected, non-diabetic mice were randomly assigned to two groups ( $\mathrm{n}=10$ mice per group): Group 1 (CONTROL), fed Teklad 8640 chow; and Group 2 (CONT+CANA), fed Teklad 8640 chow compounded with the SGLT2 inhibitor, canagliflozin, at $62.5 \mathrm{ppm}$. At the same time, agematched STZ-injected, confirmed diabetic mice, were randomly assigned to four treatment groups ( $\mathrm{n}=10$ per group): Group 3 (STZ), fed Teklad 8640 chow; Group 4 (STZ+INS), fed Teklad 8640 chow and treated with insulin via ALZET $^{\circledR}$ minipump (insulin dose: 0.125 units/day; as Humulin R insulin, Eli Lilly and Co., Indianapolis, IN); Group 5: (STZ +CANA), fed Teklad 8640 chow containing canagliflozin at 50 ppm; or Group 6: (STZ +BOTH), fed Teklad 8640 chow containing canagliflozin (50 ppm) and treated with insulin via mini pump (0.125 units/day). Diabetic mice were fed chow containing a slightly lower canagliflozin concentration (50 ppm vs. $62.5 \mathrm{ppm}$ ) to offset the polyphagia observed in diabetic mice. A comparison group of non-diabetic mice treated with insulin could not be justified due to the risk and likelihood of hypoglycemia. All mice were maintained in a 12hour light-dark cycle, and provided ad libitum access to water and to their assigned food for the next 9 weeks. Body weights and cumulative food intake were measured weekly for each animal, so as to quantify drug exposure; canagliflozin intake during the 9 week treatment 
period was similar in all groups receiving this drug: CONT+CANA, dose range: 10.5-16.5 $\mathrm{mg} / \mathrm{kg} /$ day (mean $\pm \mathrm{SE}: 14.9 \pm 0.6) ; \mathrm{STZ}+\mathrm{CANA}, 12.0-16.8 \mathrm{mg} / \mathrm{kg} /$ day $(14.9 \pm 0.5) ; \mathrm{STZ}$ + BOTH, $12.2-16.1 \mathrm{mg} / \mathrm{kg} /$ day $(13.9 \pm 0.4)$.

During the 8th week of treatment, mice were transferred to individual metabolic cages for urine collection. Thereafter, for dynamic bone histomorphometry analyses, mice were injected (i.p.) with calcein $(20 \mathrm{mg} / \mathrm{kg}$ ), in a total injection volume of $\sim 200 \mu \mathrm{l}$, at 10 and 3 days prior to euthanasia. Intraperitoneal (ip) glucose tolerance testing (ipGTT) was also performed during the final week of treatment. For the ipGTT, mice were weighed and then fasted for 4-5 hours with free access to water. Fasting blood glucose (BG) was measured via glucometer (OneTouch ${ }^{\circledR}$ Ultra ${ }^{\circledR} 2$ Blood Glucose Monitoring System, Lifescan, Inc., Milpitas, CA). A volume of $20 \%$ glucose was then injected ip (1.5 mg/gm) and BG measurements were obtained at 15, 30, 45, 60, 90, 120, and 240 minutes following glucose injection. Thereby, glycemic control was assessed: 1) as area-under-curve (AUC) for glucose measurements obtained during glucose tolerance testing (ipGTT); 2) by fasting BG measurement at week 8, via glucometer; and 3) by trunk blood (end of study) Hemoglobin A1c (HbA1c), using a mouse HbA1c whole blood assay (Crystal Chem; Downers Grove, IL, \#80310).

At study end, mice were killed by isoflurane overdose followed by decapitation, and trunk blood was collected. EX vivo analyses of bone phenotype [high resolution micro-computed tomography $(\mu \mathrm{CT})$ and biomechanical testing] along with bone biomarker measurements were completed on all mice, as described in subsequent sections. Histomorphometry was completed for 5 randomly selected mice from each group. All animal procedures were approved by the Institutional Animal Care and Use Committee (IACUC) at the University of Arkansas for Medical Sciences.

\subsubsection{Assessment of Skeletal Microarchitecture}

After euthanasia, left femurs and L6 vertebrae were harvested, frozen in phosphate buffered saline (PBS) and stored at $-20^{\circ} \mathrm{C}$ until analysis. Left femur length was measured using calipers (neck to condyle groove). For bone microarchitecture analyses, the mid-shaft and distal metaphysis regions along the axis of the bone were scanned with a micro-computed tomography $(\mu \mathrm{CT})$ scanner (Scanco Medical $\mu$ CT50, Brüttisellen, Switzerland): isotropic voxel size of $6.0 \mu \mathrm{m}$, energy settings of $70 \mathrm{kVp} / 0.114 \mathrm{~mA}$, integration time of $300 \mathrm{~ms}, 1000$ projections per full rotation, and calibrated to a hydroxyapatite (HA) phantom, as we have previously described $(21,22)$. The cranial-caudal axis of each L6 vertebral body (VB) was also aligned with the long axis of the $\mu \mathrm{CT}$ tube holder and scanned while immersed in PBS, also using a $\mu \mathrm{CT}$ scanner (Scanco Medical $\mu \mathrm{CT} 50$, Brüttisellen, Switzerland): isotropic voxel size of $12.0 \mu \mathrm{m}$, energy settings of $55 \mathrm{kVp} / 0.2 \mathrm{~mA}$, integration time of $1200 \mathrm{~ms}, 1000$ projections per full rotation, and calibrated to a known density HA phantom, as we have previously described (21). For the femur, the regions of interest (ROI) included the trabecular bone of the metaphysis and the cortical bone of the diaphysis $(1.29 \mathrm{~mm}$ and 1.78 $\mathrm{mm}$ in length for mid-shaft and metaphysis, respectively). For the VB, the ROI included the trabecular bone between the end-plates and within the cortical shell. Each ROI had a unique threshold $\left(465.7 \mathrm{mgHA} / \mathrm{cm}^{3}\right.$ and $973.0 \mathrm{mgHA} / \mathrm{cm}^{3}$ for trabecular and cortical bone, 
respectively) and Gaussian noise filter (sigma of 0.2 with support of 1 for both trabecular and cortical bone) used for all scans. Standard evaluation scripts from the manufacturer (Scanco IPL v6) were used to determine the architectural and structural properties of trabecular and cortical bone, respectively.

\subsubsection{Bone Biomechanical Testing}

To determine mechanical properties of cortical bone, intact hydrated femurs were loaded to failure in the anterior-posterior direction, with posterior side in compression, at a constant displacement rate of $3 \mathrm{~mm} / \mathrm{min}$ using a three-point (3pt) bending fixture for the material testing system (Dynamight 8841, Instron, Norwood, MA), as we have previously described (21). The span between the lower supports was $8 \mathrm{~mm}$. Structural properties included the initial stiffness, the yield and peak force experienced by the mid-shaft, and work-to-fracture $\left(\mathrm{W}_{\mathrm{f}}\right.$ is area under the force vs. displacement curve); material properties included the modulus and bending strength of the cortical compartment, as estimated using standard beam theory equations, and toughness, as estimated by span-adjusted work-to-fracture divided by cross-sectional area of the bone (23). Yielding was defined as the point on the force vs. displacement curve in which the percent difference between the initial stiffness $\left(\delta_{\mathrm{i}}\right)$ and the secant stiffness $\left(\delta_{\mathrm{s}}\right)$ was $15 \%\left(100 \times\left[\delta_{\mathrm{i}}-\delta_{\mathrm{s}}\right] / \delta_{\mathrm{i}}\right)$. The $\mu \mathrm{CT}$ scans provided the moment of inertia $\left(\mathrm{I}_{\min }\right)$ and the distance between the neutral axis of bending and the outermost point in the anterior-posterior direction $\left(\mathrm{C}_{\mathrm{min}}\right)$. The force-displacement data collected from 3pt bending tests were processed using custom Matlab (The Mathworks Inc., Natick, MA) scripts to perform the calculations.

The mechanical properties of trabecular bone were determined by loading the VB in compression (cranial-to-caudal direction) until failure in displacement control at a rate of 3 $\mathrm{mm} / \mathrm{min}$. In order to ensure axial loading, a moment relief platen was used at the caudal end to allow for specimen adjustment during the test. Peak force was recorded as the measurement of the strength of the VB.

\subsubsection{Bone Histomorphometry}

Right femurs were harvested, cleaned, fixed in 70\% ethanol, dehydrated in 100\% ethanol and embedded in methylmethacrylate. Three micron sections, cut with a Microm HM360 microtome, were then stained with Mason-Goldner trichrome stain for measurement of static and dynamic parameters of bone structure, formation and resorption, as described by others (24). Measurements of bone volume fraction (BV/TV), trabecular thickness (Tb.Th), trabecular separation (Tb.Sp), \% osteoid volume (OV/BV), \% osteoid surface (OS/BS), osteoid thickness (O.Th), osteoblast number/bone length (N.Ob/B.Pm), osteoblast surface/ bone surface (Ob.S/BS), erosion surface/bone surface (ES/BS), erosion depth (E.De), osteoclast number/bone length (N.Oc/B.Pm), osteoclast surface/bone surface (Oc.S/BS), mineral apposition rate (MAR), double labels/bone surface (dLS/BS), single labels/bone surface (sLS/BS), mineralization surface/bone surface (MS/BS), bone formation rate/bone surface (BFR/BS), mineralization lag time (MLT) and osteoid maturation time (OMT) were obtained using Osteomeasure XP system (OsteoMetrics, Inc., Decatur, GA). 


\subsubsection{Biochemical Measurements}

Urine-Using urine collected from each animal during the final week of treatment, urine calcium was measured using a calcium colorimetric assay (Sigma-Aldrich Corporation, St. Louis, MO; \#MAK022) and urine creatinine was measured using an alkaline picrate chemical assay (Exocell, Inc., Philadelphia, PA; The Creatinine Companion, \#1012). Calcium concentration was normalized to urine creatinine concentration, and reported as a urine calcium/creatinine ratio (UCCR). Similarly, urine phosphate was measured using the Abcam phosphate colorimetric assay (Abcam, Cambridge, MA, \#ab65622) and normalized to urine creatinine, and reported as a urine phosphate/creatinine ratio (UPCR).

Serum-As a marker of bone formation, procollagen type $1 \mathrm{~N}$-terminal propeptide (P1NP) was measured in serum at sacrifice, using the Rat/Mouse P1NP Enzyme immunoassay (Immunodiagnostics Systems, Inc., Fountain Hills, AZ; \#AC-33F1). As a marker of bone resorption, C-terminal telopeptides of type I collagen (RatLAPs) were measured in serum using the RatLAPs ELISA (Immunodiagnostics Systems, Inc., Fountain Hills, AZ; \#AC-06F1). FGF23, an osteocyte marker that functions to inhibit renal phosphate reabsorption, independent of PTH (25), was measured using the Millipore mouse FGF-23 ELISA (EMD Millipore Corp., St. Charles, MO, \#EZMFGF23-43K).

To confirm efficacy of minipump insulin delivery (human insulin) vs. endogenous mouse insulin production, serum insulin levels were measured using a mouse ultrasensitive insulin ELISA (ALPCO, Salem, NH, \#80-INSMSU-E01), which quantifies mouse insulin but also detects human insulin, with $\sim 250 \%$ cross-reactivity to Humulin R insulin. (This assay does not cross-react with C-peptide.) Serum C-peptide levels, also a measure of endogenous insulin secretion, were quantified using a mouse C-peptide ELISA (Crystal Chem, Inc., Downers Grove, IL, \#90050).

\subsubsection{Statistical Analyses}

To analyze the data, an Analysis of Variance (ANOVA) was performed on each response variable. Variables whose distributions showed extreme skewness were log-transformed prior to analysis and variables showing unequal variation across groups were analyzed using a weighted least squares ANOVA (see Table 1 and 2 legends for more information). The overall F-test p-values were adjusted using a Benjamini-Hochberg correction (26), and each ANOVA was determined to be significant if the False Discovery Rate (FDR)-adjusted pvalue was at most 0.05 . Following the ANOVA, for significant variables post-hoc two-tailed $\mathrm{t}$-tests were performed about comparisons of interest. A multiple testing correction for posthoc comparisons from all significant variables together was performed using the BenjaminiHochberg adjustment, and each test was called significant if the FDR-adjusted p-value was at most 0.05 .

For each of thirteen bone parameters of interest (Femur: Ct.Ar, Tt.Ar, Imin, Ct.Th, Ct.TMD, Peak Force, Bending Strength, Toughness; Vertebral Body: BV/TV, Tb.N, Tb.Th, Tb.TMD, Peak Force), a multiple linear regression model was fit with the following explanatory variables: treatment group, RatLAPs, UCCR, ipGTT AUC, Fasting BG, HbA1c, and body weight (weekly weights averaged over the 9-week treatment period). The overall F-tests of 
each model were determined to be significant if the p-value was at most 0.05 , after using a Benjamini-Hochberg correction for the 13 overall F-tests. Then, for the variables with significant overall F-tests, post-hoc tests (partial F-tests) were run for comparisons of interest. A Benjamini-Hochberg correction was performed on all 26 post-hoc tests and both raw and FDR adjusted p-values were determined. See Table 3 for additional details. All analyses were performed in SAS Version 9.3 or above (SAS Institute Inc., Cary, NC).

\subsection{RESULTS}

\subsubsection{Disease and treatment effects on metabolic control}

Consistent with expectations for STZ treatment, untreated diabetic mice (group 3: STZ) exhibited fasting (Table 1) and random hyperglycemia (Fig. 1: BG Trends and Fig. 2B: ipGTT AUC), along with a marked increase in HbA1c (Fig. 2A), when compared to nondiabetic controls (groups 1,2). No significant differences in glycemic control were evident between vehicle and CANA treatment within the control groups ( 1 vs. $2, \mathrm{p}=0.99)$; and moreover, hypoglycemia was not apparent among CANA-treated control mice (group 2).

In comparison to the untreated diabetic mice (group 3), among treated diabetic mice (groups 4-6), significant and sustained improvements in metabolic control, as indicated by Fasting BG (Table 1), sequential blood glucose (BG) measurements (Fig. 1D-F), and HbA1c (Fig. 2A) occurred with CANA treatment alone (group 5: STZ+CANA), and even more so than with insulin treatment alone (group 4: STZ+INS). In contrast, glucose tolerance testing (Fig 2B; ipGTT AUC) revealed a greater improvement in post-glucose challenge glycemia with insulin treatment. However, co-therapy with CANA and insulin (group 6: STZ+BOTH) produced the greatest overall improvement in all three indicators of glycemic control (Fasting BG, HbAlc, and ipGTT AUC), returning these parameters to normal at study end (6 vs. 1 or 6 vs. 2, NS for all).

Measurement of serum insulin levels (Fig. 2C) confirmed that insulin treatment by minipump continuous infusion increased the circulating insulin levels of diabetic mice (STZ + INS and STZ+BOTH); and at the end of the study period, insulin values in these groups were not statistically different from control mice (1 vs. 4 or 2 vs. 6 , NS); however, insulin concentrations in groups 1, 2, 3 and 5 reflect endogenous mouse insulin production, whereas values for groups 4 and 6 primarily quantify exogenous delivery of human insulin. Endogenous insulin production, as reflected by measurements of serum C-peptide (Fig. 2D), was significantly lower in diabetic mice compared with control mice (1 vs. 3, p<0.001). However, in DM mice treated with CANA, either alone (STZ+CANA) or in combination with insulin (STZ+BOTH), a significant difference in C-peptide was observed compared to STZ only (group 3), indicating an increase in endogenous insulin production in response to CANA treatment ( 3 vs. $5, \mathrm{p}=0.004 ; 3$ vs. $6, \mathrm{p}=0.002$ ).

\subsubsection{Disease and treatment effects on bone biomarkers}

As shown in Figure 3, P1NP (Fig. 3A), a marker of bone formation, was reduced in untreated diabetic mice compared to control mice ( 1 vs. $3, \mathrm{p}=0.003$ ); P1NP did not significantly change with either CANA or insulin mono-therapy compared to untreated 
diabetic mice. With co-therapy, a modest increase in P1NP values was observed, compared with untreated diabetic mice, which did not reach statistical significance ( 3 vs. $6, p=0.11$ ).

In contrast, RatLAPs (Fig. 3B), a marker of bone resorption, was increased in diabetic mice, as compared to control mice ( 1 vs. 3, 2 vs. 5 ; $\mathrm{p}<0.001$ for both). Insulin treatment significantly lowered RatLAPS to near-normal values ( 3 vs. $4, \mathrm{p}=0.015$ ). However, this bone resorption marker remained high and indistinguishable from untreated diabetic mice in either DM group receiving CANA (STZ+CANA or STZ+BOTH), despite the concurrent improvements in glucose control that occurred in these groups ( 3 vs. 5 or 3 vs. 6, NS; 2 vs. 5 or 2 vs. $6, \mathrm{p}<0.001$ for both). Similarly, urine calcium excretion (UCCR, Fig. 3C) was significantly increased in diabetic mice ( 1 vs. $3, \mathrm{p}<0.001 ; 2$ vs. $5, \mathrm{p}=0.012)$. UCCR improved with either insulin or CANA treatment of diabetic mice or with co-therapy (3 vs. $4 ; 3$ vs. $5 ; 3$ vs. $6 ; \mathrm{p}<0.001$ for all), although mean UCCR values in either DM group receiving CANA (STZ+CANA, STZ+BOTH) were modestly higher than in the STZ+INS group. Moreover, a significant increase in UCCR was also noted in control mice treated with CANA ( 1 vs. $2, \mathrm{p}=0.042$ ). Overall, an increase in urinary calcium excretion was seen in untreated diabetic mice and in mice exposed to CANA, but lessened in those DM mice experiencing improved glucose control.

Serum FGF23 values (Fig. 3D) were increased in untreated diabetic mice compared with control mice ( 1 vs. 3 , p=0.005); among DM mice treated with insulin mono-therapy, mean FGF23 values decreased to values which were again not significantly different than control values ( 1 vs. 4 , NS; 3 vs. 4 , $\mathrm{p}=0.002$ ). In contrast, treatment with CANA alone did not restore FGF23 values to normal ( 3 vs. 5 , NS; 2 vs. 5 , p <0.001). When co-therapy was administered, a significant reduction in FGF23 was again observed (similar to insulin monotherapy) ( 3 vs. 6, $\mathrm{p}=0.049$ ). Despite these group-specific changes in serum FGF23 concentration, there were no significant differences in urine phosphate-to-creatinine ratio (UPCR) between the treatment groups (Group 1, mean \pm SE: $16.2 \pm 3.0 \mathrm{gm} / \mathrm{mg}$; Group 2: 17.9 \pm 3.0; Group 3: $14.1 \pm 3.3$; Group 4: $11.6 \pm 3.1$; Group 5: $14.9 \pm 3.0$; Group 6: 16.9 \pm 3.1 .

\subsubsection{Disease and treatment effects on bone microarchitecture, material and structural qualities of the appendicular skeleton}

In the femur, untreated diabetes caused significant deficits in cortical bone area (Ct.Ar), total cross-sectional area (Tt.Ar), moment of inertia $\left(\mathrm{I}_{\mathrm{min}}\right)$, and cortical thickness $(\mathrm{Ct} . \mathrm{Th})$, along with an increase in cortical porosity (Ct.Po) (see Table 1 for p-values; 1 vs. 3). Significant deficits in trabecular bone of the femur were also apparent; specifically, reductions in bone volume fraction (BV/TV), trabecular number (Tb.N), trabecular thickness (Tb.Th) and trabecular tissue mineral density (Tb.TMD), along with an increase in trabecular separation ( $\mathrm{Tb} . \mathrm{Sp}$ ) were apparent in untreated DM mice in relation to non-diabetic controls. These deficits in bone microarchitecture were accompanied by changes in structural strength of the femur (bending), including both a decrease in stiffness and peak force endured by the midshaft. With respect to the estimated material properties of the cortical bone (femur only), STZ-induced diabetes also decreased bending strength, toughness, and post-yield displacement (PYD). 
Treatment with either CANA (STZ+CANA) or insulin (STZ+INS) alone partially rectified the diabetic cortical bone micro-architectural deficits of the femur, although these individual drug improvements were not always statistically significant (Table 1). However, when used in combination (STZ+BOTH), and in conjunction with normalization of glycemic control, significant recovery of the femur cortical microarchitecture (Ct.Ar, $\mathrm{I}_{\min }, \mathrm{Ct} . \mathrm{Th}, \mathrm{Ct.TMD}$, Ct.Po) and fracture resistance of the femur mid-shaft (peak force, PYD, work-to-fracture, toughness) were evident in mice receiving co-therapy. Moreover, for all these cortical parameters except porosity (Ct.Po), treatment effects were additive (i.e., statistical analysis showed no evidence against additivity); whereas, the improvement in Ct.Po was greatest with CANA ( 4 vs. 5, p=0.05). Similar to cortical bone, within trabecular bone of the femur restoration of BV/TV, Conn.D, Tb.N, Tb.Th, and Tb.Sp was greatest with co-therapy, and treatment effects on these parameters were also additive. Together, this suggested that treatment effects were related either: 1) to additive effects of SGLT2I plus insulin on glucose-lowering; or 2) to skeletal effects operating through distinct but additive pathways.

\subsubsection{Disease and treatment effects on bone microarchitecture and strength of the axial skeleton}

Deficits in trabecular bone of the vertebral body (VB) were also seen in untreated DM mice (see Table 2 for p-values), including a reduced bone volume fraction (VB BV/TV), trabecular thickness (VB Tb.Th), and trabecular TMD (VB Tb.TMD), contributing to a lower whole-bone strength of the VB in compression (VB Peak Force; Table 2). Insulin treatment, more so than CANA, resulted in significant improvements in BV/TV, Tb.N, Tb.Th, Tb.TMD and VB strength. Changes in Tb.Th and Tb.TMD were not additive, with greater beneficial increments attributable to insulin alone, particularly for Tb.TMD. Moreover, Tb.TMD was significantly lower in control mice treated with CANA ( $\mathrm{p}=0.05)$, indicating an overall detrimental drug-effect of CANA on vertebral Tb.TMD.

\subsubsection{Bone Histomorphometry}

Perhaps due to smaller sample sizes ( $\mathrm{n}=5$ per group) along with multiple test groups, significant between-group differences by histomorphometry were apparent only for bone volume fraction (BV/TV), trabecular separation (Tb.Sp), \% osteoid volume (OV/BV), and \% osteoid surface (OS/BS), as shown in Figure 4. Bone histomorphometry did not demonstrate significant between group differences for Tb.Th, O.Th, N.Ob/B.Pm, Ob.S/BS, ES/BS, E.De, N.Oc/B.Pm, Oc.S/BS, MAR, dLS/BS, sLS/BS, MS/BS, BFR/BS, MLT or OMT. However, consistent with a state of attenuated bone formation, BFR/BS and MAR did demonstrate noticeably lower values in diabetes, which trended toward normalization with drug treatment (BFR/BS. CONTROL: $10.37 \pm 1.43 \mathrm{~mm}^{3} / \mathrm{cm}^{2} / \mathrm{y}$; CONT+CANA: $10.28 \pm 1.60 ;$ STZ: 4.97 \pm 1.43 ; STZ+INS: $7.14 \pm 1.43$; STZ+CANA: $8.82 \pm 1.43$; STZ+BOTH: $7.29 \pm 1.43$; Overall ANOVA p-value $=0.134$. MAR. CONTROL: $1.32 \pm 0.10 \mu \mathrm{m} /$ day; CONT+CANA: 1.28 \pm 0.05 ; STZ: $0.95 \pm 0.10$; STZ+INS: $1.24 \pm 0.06$; STZ+CANA: $1.33 \pm 0.12$; STZ+BOTH: $1.30 \pm 0.19$; Overall ANOVA p-value $=0.104$ ).

Treatment effects on BV/TV and Tb.Sp were additive (i.e., by statistical analysis, no evidence against additive treatment effects was found). In contrast, a significant non-additive treatment effect on $\%$ osteoid volume and $\%$ osteoid surface was found; rather, compared to 
untreated diabetic bones (group 3), a greater increase in OV/BV and OS/BS occurred in bones of CANA-treated DM mice (Fig. 4: group 5).

\subsubsection{Multiple linear regression modeling}

As shown in Table 3, all thirteen bone parameters were well explained by at least one of the following: treatment group, RatLAPs, UCCR, ipGTT AUC, Fasting BG, HbA1c, and average body weight (Table 3, Overall p-values). In particular, after accounting for body weight and bone resorption parameters, treatment group or glycemic control parameters were still helpful in explaining microarchitecture deficits in cortical bone of the femur (Ct.Ar, Ct.Th, Ct.TMD); additionally, the resultant decrements in femur structural strength (bending, peak force) and bone toughness were significantly explained by differences in glycemic status across the groups (Table 3, Post-Hoc Test 1 p-values). Similarly, after accounting for body weight and glycemic control parameters, treatment group or bone resorption status was still helpful in explaining the structural strength of the femur (bending) and select cortical changes (Ct.Ar, Ct.TMD) across the groups (Table 3, Post-Hoc Test 2 pvalues). In comparison, whole-bone strength of the vertebral body (VB peak force) was predominantly explained by differences in glycemic control; after accounting for glycemic control and treatment group differences, bone resorption was no longer helpful in explaining VB peak force differences (Post-Hoc Test 1: $\mathrm{p}=0.004$; Post-Hoc Test 2: NS).

\subsection{DISCUSSION}

Within this model of hypoinsulinemic diabetic bone disease (DBD), significant deficits in both appendicular and axial bone microarchitecture and bone strength were evident, along with bone biomarker derangements indicative of reduced bone formation, increased bone resorption, exaggerated urinary mineral loss, and a secondary increase in FGF23. These diabetes-associated skeletal findings are consistent with our previous reports $(21,27,28)$. Herein, however, near-complete normalization of glycemic control with relevant therapies resulted in a significant improvement in all cortical bone microarchitecture parameters, with a return to near-normal for all parameters except Ct.Po and Ct.TMD. Similarly, deficits in VB trabecular bone were also normalized in tandem with the metabolic improvements induced by co-therapy. As a result, bone strength of the femur and vertebral body were largely restored by co-therapy, consistent with explanatory modeling that suggested a predictive effect of glycemic status on bone phenotype. Interestingly, however, despite these structural improvements in bone, the STZ-induced increase in biomarkers indicative of bone resorption (RatLAPs, UCCR) persisted even with co-therapy, indicating that skeletal turnover was increased and not solely dependent upon glycemic status.

When comparing the current study to our previous results, we do recognize some variability between experiments within this rodent model of T1D. For example, despite similar CANA drug dosing and mode of drug administration, CANA-monotherapy in the current study lowered the mean blood glucose in group 5 by $\sim 50 \%$ compared with group 3, whereas in our previous investigation of the effects of SGLT2I treatment on streptozotocin (STZ)induced long-term diabetes (21), only a $\sim 35 \%$ reduction in blood glucose was achieved. This greater effect on glycemic control in the current study likely contributed to greater 
improvements in bone microarchitecture with CANA mono-therapy (Table 1, 3 vs. 5 comparisons) than were reported in our original study (21) (i.e., a higher BV/TV in the distal femur metaphysis in CANA-treated diabetic mice in the original study was not statistically significant). We also noted some discrepancies in bone biomarker concentrations in the current data, as compared with our previous investigation (21). Specifically, in our previous report, we demonstrated a further significant increase in RatLaps in diabetic mice treated with CANA, compared with untreated diabetic mice. Additionally, we reported an increase in FGF23 in control mice treated with CANA, compared with untreated control mice. These two findings were not replicated in the present study. However, the sample size per treatment group in the first study was twice the sample size used in the current study, possibly limiting the power of our analysis to reproduce these findings.

When comparing insulin mono-therapy with CANA mono-therapy, certain unique features of SGLT2I therapy were observed. Specifically, CANA-treated mice demonstrated an increase in urinary calcium loss. The phosphaturic hormone, FGF23, also remained high in CANA-treated diabetic mice perhaps compensating for drug-induced renal phosphate reabsorption. These features could contribute to ongoing mineral loss following CANA exposure. Consistent with this hypothesis, a significant decrease in appendicular cortical thickness (Ct.Th) and in axial bone density (VB Tb.TMD) was identified even in control mice exposed to CANA. Finally, in diabetic mice treated with CANA, alone or in combination with insulin (group 5 or 6), evidence of bone resorption persisted despite the improved metabolic milieu evident in these two groups. Together, these observations could suggest that, over time, certain CANA-induced skeletal consequences might detract from the drug-induced therapeutic improvements in glycemic control, at least as they relate to diabetic bone disease.

Our pre-clinical findings are consistent with a recent pharmacodynamic analysis in ten healthy (non-diabetic) adults treated acutely (days 1-5) with canagliflozin. In these subjects, a significant increase in serum phosphate, FGF23 and PTH was noted, which the authors postulate as evidence of a secondary hyperparathyroidism in response to drug exposure (29). Despite this, biochemical factors directly relating to the increased fracture risk demonstrated in T2D patients treated with either canagliflozin (18) or dapagliflozin (19) remain unclear. Retrospective pooled dataset analysis from placebo-controlled, Phase III studies treating adult T2D patients with either canagliflozin (CANA) (30) or dapagliflozin (DAPA) $(19,31)$ have identified modest, but clinically insignificant increases in serum phosphate (CANA, DAPA), magnesium (CANA, DAPA), osteocalcin (CANA) (32), parathyroid hormone (DAPA) and collagen type-1 beta-carboxy telopeptide (CANA, DAPA) $(30,32,33)$ concentrations in patients treated with these SGLT2Is. In contrast, pooled clinical data analysis for empagliflozin (34) examining >8500 T2D patients from 17 placebo-controlled Phase I to III trials plus 6 extension trials (study duration up to 104 weeks), found no increase in fracture incidence and no significant change in serum calcium, phosphate, magnesium, parathyroid hormone, alkaline phosphatase, or urinary N-telopeptide concentration among empagliflozin-treated subjects, perhaps suggesting drug-specific differences in ultimate skeletal impact. 
Although high affinity facilitative glucose transporters (GLUTs) are expressed in osteoblasts (GLUT1 and GLUT3) and osteoclasts (GLUT1) (35-37), sodium-dependent glucose cotransporters (i.e. SGLT1 and SGLT2) have not been identified in bone cells. To determine whether effects of SGLT2I therapy specifically on bone phenotype might result from altered glucose transport at the cellular level in bone, we have previously examined the expression of SGLT1 and SGLT2 by quantitative RT-PCR in mouse calvarial osteoblasts, C3H10T1/2 mesenchymal stem cells, and MC3T3-E1 cells at various stages of differentiation. Expression was also analyzed in in vitro differentiated macrophages, pre-osteoclasts and mature osteoclasts from mouse bone marrow. SGLT1 and SGLT2 were not detected in cells of the osteoclast lineage and SGLT2 was not detected in any of the osteoblast cell lines (Supplemental Table 1). SGLT1 was detected in MC3T3-E1 differentiating osteoblasts (weeks 2-4), albeit at levels <1\% of that observed in the kidney (Supplemental Table 1). These findings are consistent with the hypothesis that any SGLT2I-related skeletal effects are more likely the result of systemic changes in bone-mineral homeostasis and glycemia, rather than disruption of SGLT2-dependent glucose transport in bone cells.

Beyond our observed skeletal outcomes, a potential beneficial effect on pancreatic $\beta$-cell function was seen with SGLT2I drug treatment. Consistent with STZ-induced $\beta$-cell toxicity, mean C-peptide concentration, a reflection of endogenous insulin secretion, was significantly reduced in all diabetic mice (Groups 3-6) relative to control levels. Conversely, those groups treated with CANA, either alone or in combination with insulin, demonstrated a significant, $\sim 5$-fold increase in C-peptide, suggesting some recovery of $\beta$-cell function and/or $\beta$-cell mass following CANA treatment. Similar beneficial effects of SGLT2Is on pancreatic $\beta$-cell mass and $\beta$-cell function have been seen in STZ-induced type 1 diabetic rats (empagliflozin) (38), obese type 2 diabetic $\mathrm{db} / \mathrm{db}$ mice (tofogliflozin, luseogliflozin) $(39,40)$, and in adult patients with T2D $(41,42)$. In models of T2D, certainly, protection of $\beta$-cells from glucotoxicity could contribute to enhanced $\beta$-cell function. However, in our model of insulin-deficiency T1D, glucose-lowering with insulin therapy alone did not similarly improve C-peptide concentrations, suggesting that SGLT2I effects on $\beta$-cell mass could extend beyond their effects on glucotoxicity. It remains to be seen whether SGLT2I drugs impact $\beta$-cell proliferation in models of autoimmune-mediated diabetes. However, if confirmed, enhanced $\beta$-cell function in response to SGLT2I therapy could represent an indirect anabolic mechanism whereby SGLT2I drugs impact bone.

Interestingly, because the primary mechanism of SGLT2I action is one of glucosuria, independent of $\beta$-cell function, hypoglycemia potential is thought to be low. However, in studies utilizing empagliflozin as add-on to insulin or metformin + sulfonylurea therapy, the incidence of hypoglycemia was higher with empagliflozin than with placebo (34), potentially also forecasting differences in $\beta$-cell responsivity to different drugs in the SGLT2I class. Unfortunately, a greater risk of hypoglycemia might also contribute to a greater fall-related risk of fracture in these patients.

Certain limitations of this study must be recognized. First, this study involves the use of only one SGLT2I drug, given at only one dose. Hence, these observations may not be generalizable to other drugs within the SGLT2I drug class. However, our intent was to identify a drug-dose combination which would closely approximate normoglycemia, without 
hypoglycemia, in a model of insulin-deficiency diabetes (i.e., T1D); this goal was, in fact, achieved by our study design. Secondly, while the DBA/2J strain was chosen for its propensity to develop diabetic complications, and for its consistent DBD phenotype $(21,28)$, this study has not been replicated in other rodent models of hypoinsulinemic diabetes such as the non-obese diabetic (NOD) mouse, the Akita mouse, or other STZ-treated mouse strains. Hence, these observations, particularly as they relate to $\beta$-cell function, might not be generalizable to other animal models. Additionally, while this study was conducted to examine skeletal effects of SGLT2 inhibition in a hypoinsulinemic model of diabetes, the current clinical relevance of these findings must be interpreted cautiously since, at this time, SGLT2I therapy is only FDA-approved for treatment of T2D, a condition which is often complicated by insulin resistance, obesity, and secondary comorbidities which indirectly also influence skeletal homeostasis. Our model does not replicate these T2D confounding variables, nor does it replicate the impact of SGLT2I-induced weight loss on skeletal or clinical outcomes. Moreover, pharmacologic effects of SGLT2 inhibitors on rodent physiology may, indeed, be distinct from effects seen in humans.

In summary, long-term normalization of glycemic control with SGLT2I plus insulin cotherapy is efficacious in preventing the occurrence of diabetic bone disease in an STZinduced model of hypoinsulinemic diabetes. However, despite clear benefits in glucoselowering, SGLT2Is alone may also impart secondary effects on bone turnover which warrant continued surveillance as SGLT2-inhibitor utilization becomes more routine, for T2D and perhaps also for T1D.

\section{Supplementary Material}

Refer to Web version on PubMed Central for supplementary material.

\section{Acknowledgments and Funding}

This work was supported by grants from the Children's University Medical Group Fund of the Arkansas Children's Hospital Research Institute (ACHRI; to K.M.T.), the Arkansas Biosciences Institute (to J.L.F.), and in part by National Institutes of Health Grants R01DK055653 (to J.L.F.), R21AR070620 (to K.M.T and J.S.N.) and C06RR16517 (to ACHRI), as well as the Department of Veterans Affairs, Veterans Health Administration, Office of Research and Development 1I01BX001018 (to J.S.N.). Additional funding was provided by the University of Kentucky Barnstable Brown Diabetes Center Endowment. The authors greatly appreciate the laboratory technical assistance provided by Gael Cockrell and Elizabeth Wahl at ACHRI, and are grateful for the gift of macrophages, pre-osteoclasts and mature osteoclasts from mouse bone marrow provided by Maria Almeida, $\mathrm{PhD}$ (University of Arkansas for Medical Sciences). The authors also appreciate the academic guidance of Dr. Richard Charnigo (Biostatistics, University of Kentucky).

\section{References}

1. Lecka-Czernik, B., Fowlkes, J., editors. Diabetic Bone Disease. 1 ed.. Springer International Publishing; 2016. p. 230

2. Ferrannini E, Ramos SJ, Salsali A, Tang W, List JF. Dapagliflozin monotherapy in type 2 diabetic patients with inadequate glycemic control by diet and exercise: a randomized, double-blind, placebo-controlled, phase 3 trial. Diabetes care. 2010; 33(10):2217-24. doi: 10.2337/dc10-0612. PubMed PMID: 20566676; PubMed Central PMCID: PMC2945163. [PubMed: 20566676]

3. Kaku K, Watada H, Iwamoto Y, Utsunomiya K, Terauchi Y, Tobe K, Tanizawa Y, Araki E, Ueda M, Suganami H, Watanabe D, Tofogliflozin 003, Study G. Efficacy and safety of monotherapy with the novel sodium/glucose cotransporter-2 inhibitor tofogliflozin in Japanese patients with type 2 
diabetes mellitus: a combined Phase 2 and 3 randomized, placebo-controlled, double-blind, parallelgroup comparative study. Cardiovascular diabetology. 2014; 13:65. doi: 10.1186/1475-2840-13-65. PubMed PMID: 24678906; PubMed Central PMCID: PMC4021346. [PubMed: 24678906]

4. Wilding JP, Woo V, Soler NG, Pahor A, Sugg J, Rohwedder K, Parikh S, Dapagliflozin 006 Study G. Long-term efficacy of dapagliflozin in patients with type 2 diabetes mellitus receiving high doses of insulin: a randomized trial. Annals of internal medicine. 2012; 156(6):405-15. doi: 10.7326/0003-4819-156-6-201203200-00003. PubMed PMID: 22431673. [PubMed: 22431673]

5. Rosenstock J, Jelaska A, Frappin G, Salsali A, Kim G, Woerle HJ, Broedl UC, Investigators E-RMT. Improved glucose control with weight loss, lower insulin doses, and no increased hypoglycemia with empagliflozin added to titrated multiple daily injections of insulin in obese inadequately controlled type 2 diabetes. Diabetes care. 2014; 37(7):1815-23. doi: 10.2337/dc13-3055. PubMed PMID: 24929430. [PubMed: 24929430]

6. DeFronzo RA, Lewin A, Patel S, Liu D, Kaste R, Woerle HJ, Broedl UC. Combination of empagliflozin and linagliptin as second-line therapy in subjects with type 2 diabetes inadequately controlled on metformin. Diabetes care. 2015; 38(3):384-93. doi: 10.2337/dc14-2364. PubMed PMID: 25583754. [PubMed: 25583754]

7. Guthrie RM. Clinical use of dipeptidyl peptidase-4 and sodium-glucose cotransporter 2 inhibitors in combination therapy for type 2 diabetes mellitus. Postgraduate medicine. 2015; 127(5):463-79. doi: 10.1080/00325481.2015.1044756. PubMed PMID: 25956345. [PubMed: 25956345]

8. Kovacs CS, Seshiah V, Merker L, Christiansen AV, Roux F, Salsali A, Kim G, Stella P, Woerle HJ, Broedl UC, investigators E-REP. Empagliflozin as Add-on Therapy to Pioglitazone With or Without Metformin in Patients With Type 2 Diabetes Mellitus. Clinical therapeutics. 2015 doi: 10.1016/ j.clinthera.2015.05.511. PubMed PMID: 26138864.

9. Mathieu C, Ranetti AE, Li D, Ekholm E, Cook W, Hirshberg B, Chen H, Hansen L, Iqbal N. A Randomized, Double-Blind, Phase 3 Trial of Triple Therapy With Dapagliflozin Add-on to Saxagliptin Plus Metformin in Type 2 Diabetes. Diabetes care. 2015 doi: 10.2337/dc15-0779. PubMed PMID: 26246458.

10. Perkins BA, Cherney DZ, Partridge H, Soleymanlou N, Tschirhart H, Zinman B, Fagan NM, Kaspers S, Woerle HJ, Broedl UC, Johansen OE. Sodium-glucose cotransporter 2 inhibition and glycemic control in type 1 diabetes: results of an 8-week open-label proof-of-concept trial. Diabetes care. 2014; 37(5):1480-3. doi: 10.2337/dc13-2338. PubMed PMID: 24595630. [PubMed: 24595630]

11. Bell DS. Case Reports That Illustrate the Efficacy of SGLT2 Inhibitors in the Type 1 Diabetic Patient. Case reports in endocrinology. 2015; 2015:676191. doi: 10.1155/2015/676191. PubMed PMID: 25785209; PubMed Central PMCID: PMC4345240. [PubMed: 25785209]

12. Peters AL, Buschur EO, Buse JB, Cohan P, Diner JC, Hirsch IB. Euglycemic Diabetic Ketoacidosis: A Potential Complication of Treatment With Sodium-Glucose Cotransporter 2 Inhibition. Diabetes care. 2015; 38(9):1687-93. doi: 10.2337/dc15-0843. PubMed PMID: 26078479; PubMed Central PMCID: PMC4542270. [PubMed: 26078479]

13. Sands AT, Zambrowicz BP, Rosenstock J, Lapuerta P, Bode BW, Garg SK, Buse JB, Banks P, Heptulla R, Rendell M, Cefalu WT, Strumph P. Sotagliflozin, a Dual SGLT1 and SGLT2 Inhibitor, as Adjunct Therapy to Insulin in Type 1 Diabetes. Diabetes care. 2015 doi: 10.2337/dc14-2806. PubMed PMID: 26049551.

14. Komoroski B, Vachharajani N, Boulton D, Kornhauser D, Geraldes M, Li L, Pfister M. Dapagliflozin, a novel SGLT2 inhibitor, induces dose-dependent glucosuria in healthy subjects. Clinical pharmacology and therapeutics. 2009; 85(5):520-6. doi: 10.1038/clpt.2008.251. PubMed PMID: 19129748. [PubMed: 19129748]

15. Sha S, Devineni D, Ghosh A, Polidori D, Chien S, Wexler D, Shalayda K, Demarest K, Rothenberg P. Canagliflozin, a novel inhibitor of sodium glucose co-transporter 2, dose dependently reduces calculated renal threshold for glucose excretion and increases urinary glucose excretion in healthy subjects. Diabetes, obesity \& metabolism. 2011; 13(7):669-72. doi: 10.1111/j. 1463-1326.2011.01406.x. PubMed PMID: 21457428.

16. Nauck MA, Del Prato S, Duran-Garcia S, Rohwedder K, Langkilde AM, Sugg J, Parikh SJ. Durability of glycaemic efficacy over 2 years with dapagliflozin versus glipizide as add-on therapies in patients whose type 2 diabetes mellitus is inadequately controlled with metformin. 
Diabetes, obesity \& metabolism. 2014; 16(11):1111-20. doi: 10.1111/dom.12327. PubMed PMID: 24919526.

17. Abdul-Ghani MA, Norton L, DeFronzo RA. Renal Sodium-Glucose Cotransporter Inhibition in the Management of Type 2 Diabetes Mellitus. American journal of physiology Renal physiology. 2015 ajprenal 00267 2015. doi: 10.1152/ajprenal.00267.2015. PubMed PMID: 26354881.

18. Taylor SI, Blau JE, Rother KI. Possible adverse effects of SGLT2 inhibitors on bone. The lancet Diabetes \& endocrinology. 2015; 3(1):8-10. doi: 10.1016/S2213-8587(14)70227-X. PubMed PMID: 25523498. [PubMed: 25523498]

19. Kohan DE, Fioretto P, Tang W, List JF. Long-term study of patients with type 2 diabetes and moderate renal impairment shows that dapagliflozin reduces weight and blood pressure but does not improve glycemic control. Kidney international. 2014; 85(4):962-71. doi: 10.1038/ki. 2013.356. PubMed PMID: 24067431; PubMed Central PMCID: PMC3973038. [PubMed: 24067431]

20. Gregorio F, Cristallini S, Santeusanio F, Filipponi P, Fumelli P. Osteopenia associated with noninsulin-dependent diabetes mellitus: what are the causes? Diabetes research and clinical practice. 1994; 23(1):43-54. PubMed PMID: 8013262. [PubMed: 8013262]

21. Thrailkill KM, Clay Bunn R, Nyman JS, Rettiganti MR, Cockrell GE, Wahl EC, Uppuganti S, Lumpkin CK Jr. Fowlkes JL. SGLT2 inhibitor therapy improves blood glucose but does not prevent diabetic bone disease in diabetic DBA/2J male mice. Bone. 2015 doi: 10.1016/j.bone. 2015.07.025. PubMed PMID: 26211996.

22. Fowlkes JL, Nyman JS, Bunn RC, Cockrell GE, Wahl EC, Rettiganti MR, Lumpkin CK Jr. Thrailkill KM. Effects of long-term doxycycline on bone quality and strength in diabetic male DBA/2J mice. Bone reports. 2015; 1:16-9. doi: 10.1016/j.bonr.2014.10.001. PubMed PMID: 25685827; PubMed Central PMCID: PMC4324548. [PubMed: 25685827]

23. Uppuganti S, Granke M, Makowski AJ, Does MD, Nyman JS. Age-related changes in the fracture resistance of male Fischer F344 rat bone. Bone. 2016; 83:220-32. doi: 10.1016/j.bone. 2015.11.009. PubMed PMID: 26610688; PubMed Central PMCID: PMC4724327. [PubMed: 26610688]

24. Zhang M, Xuan S, Bouxsein ML, von Stechow D, Akeno N, Faugere MC, Malluche H, Zhao G, Rosen CJ, Efstratiadis A, Clemens TL. Osteoblast-specific knockout of the insulin-like growth factor (IGF) receptor gene reveals an essential role of IGF signaling in bone matrix mineralization. The Journal of biological chemistry. 2002; 277(46):44005-12. doi: 10.1074/jbc.M208265200. PubMed PMID: 12215457. [PubMed: 12215457]

25. Quarles LD. Role of FGF23 in vitamin D and phosphate metabolism: implications in chronic kidney disease. Experimental cell research. 2012; 318(9):1040-8. doi: 10.1016/j.yexcr. 2012.02.027. PubMed PMID: 22421513; PubMed Central PMCID: PMC3336874. [PubMed: 22421513]

26. Benjamini Y, Hochberg Y. Controlling the False Discovery Rate: A Practical and Powerful Approach to Multiple Testing. Journal of the Royal Statistical Society. 1995; 57(1):289-300.

27. Thrailkill KM, Liu L, Wahl EC, Bunn RC, Perrien DS, Cockrell GE, Skinner RA, Hogue WR, Carver AA, Fowlkes JL, Aronson J, Lumpkin CK Jr. Bone formation is impaired in a model of type 1 diabetes. Diabetes. 2005; 54(10):2875-81. PubMed PMID: 16186388. [PubMed: 16186388]

28. Nyman JS, Even JL, Jo CH, Herbert EG, Murry MR, Cockrell GE, Wahl EC, Bunn RC, Lumpkin CK Jr. Fowlkes JL, Thrailkill KM. Increasing duration of type 1 diabetes perturbs the strengthstructure relationship and increases brittleness of bone. Bone. 2011; 48(4):733-40. doi: 10.1016/ j.bone.2010.12.016. PubMed PMID: 21185416; PubMed Central PMCID: PMC3062641. [PubMed: 21185416]

29. Blau, JE.Bauman, V.Piaggi, P.Collins, MT.Taylor, SI., Rother, KI., editors. Acute effects of canagliflozin on bone metabolism: Preliminary results from a randomized, placebo-controlled trial; 76th Scientific Sessions of the ADA; New Orleans, LA: American Diabetes Association. 2016;

30. Alba M, Xie J, Fung A, Desai M. The Effects of Canagliflozin, a Sodium Glucose Co-transporter 2 Inhibitor, on Mineral Metabolism and Bone in Patients With Type 2 Diabetes Mellitus. Current 
medical research and opinion. 2016:1-34. doi: 10.1080/03007995.2016.1174841. PubMed PMID: 27046479.

31. List JF, Woo V, Morales E, Tang W, Fiedorek FT. Sodium-glucose cotransport inhibition with dapagliflozin in type 2 diabetes. Diabetes care. 2009; 32(4):650-7. doi: 10.2337/dc08-1863. PubMed PMID: 19114612; PubMed Central PMCID: PMC2660449. [PubMed: 19114612]

32. Bilezikian JP, Watts NB, Usiskin K, Polidori D, Fung A, Sullivan D, Rosenthal N. Evaluation of Bone Mineral Density and Bone Biomarkers in Patients With Type 2 Diabetes Treated With Canagliflozin. The Journal of clinical endocrinology and metabolism. 2016; 101(1):44-51. doi: 10.1210/jc.2015-1860. PubMed PMID: 26580234; PubMed Central PMCID: PMC4701848. [PubMed: 26580234]

33. Ljunggren O, Bolinder J, Johansson L, Wilding J, Langkilde AM, Sjostrom CD, Sugg J, Parikh S. Dapagliflozin has no effect on markers of bone formation and resorption or bone mineral density in patients with inadequately controlled type 2 diabetes mellitus on metformin. Diabetes, obesity \& metabolism. 2012; 14(11):990-9. doi: 10.1111/j.1463-1326.2012.01630.x. PubMed PMID: 22651373.

34. Kohler S, Salsali A, Hantel S, Kaspers S, Woerle HJ, Kim G, Broedl UC. Safety and Tolerability of Empagliflozin in Patients with Type 2 Diabetes. Clinical therapeutics. 2016 doi: 10.1016/ j.clinthera.2016.03.031. PubMed PMID: 27085585.

35. Wei J, Shimazu J, Makinistoglu MP, Maurizi A, Kajimura D, Zong H, Takarada T, Lezaki T, Pessin JE, Hinoi E, Karsenty G. Glucose Uptake and Runx2 Synergize to Orchestrate Osteoblast Differentiation and Bone Formation. Cell. 2015; 161(7):1576-91. doi: 10.1016/j.cell.2015.05.029. PubMed PMID: 26091038; PubMed Central PMCID: PMC4475280. [PubMed: 26091038]

36. Thomas DM, Maher F, Rogers SD, Best JD. Expression and regulation by insulin of GLUT 3 in UMR 106-01, a clonal rat osteosarcoma cell line. Biochemical and biophysical research communications. 1996; 218(3):789-93. doi: 10.1006/bbrc.1996.0140. PubMed PMID: 8579592. [PubMed: 8579592]

37. Zoidis E, Ghirlanda-Keller C, Schmid C. Stimulation of glucose transport in osteoblastic cells by parathyroid hormone and insulin-like growth factor I. Molecular and cellular biochemistry. 2011; 348(1-2):33-42. doi: 10.1007/s11010-010-0634-z. PubMed PMID: 21076856. [PubMed: 21076856]

38. Cheng ST, Chen L, Li SY, Mayoux E, Leung PS. The Effects of Empagliflozin, an SGLT2 Inhibitor, on Pancreatic beta-Cell Mass and Glucose Homeostasis in Type 1 Diabetes. PloS one. 2016; 11(1):e0147391. doi: 10.1371/journal.pone.0147391. PubMed PMID: 26807719; PubMed Central PMCID: PMC4726656. [PubMed: 26807719]

39. Okauchi S, Shimoda M, Obata A, Kimura T, Hirukawa H, Kohara K, Mune T, Kaku K, Kaneto H. Protective effects of SGLT2 inhibitor luseogliflozin on pancreatic beta-cells in obese type 2 diabetic db/db mice. Biochemical and biophysical research communications. 2016; 470(3):772-82. doi: 10.1016/j.bbrc.2015.10.109. PubMed PMID: 26505796. [PubMed: 26505796]

40. Nagata T, Fukuzawa T, Takeda M, Fukazawa M, Mori T, Nihei T, Honda K, Suzuki Y, Kawabe Y. Tofogliflozin, a novel sodium-glucose co-transporter 2 inhibitor, improves renal and pancreatic function in db/db mice. British journal of pharmacology. 2013; 170(3):519-31. doi: 10.1111/bph. 12269. PubMed PMID: 23751087; PubMed Central PMCID: PMC3791991. [PubMed: 23751087]

41. Takahara M, Shiraiwa T, Matsuoka TA, Katakami N, Shimomura I. Ameliorated pancreatic beta cell dysfunction in type 2 diabetic patients treated with a sodium-glucose cotransporter 2 inhibitor ipragliflozin. Endocrine journal. 2015; 62(1):77-86. doi: 10.1507/endocrj.EJ14-0335. PubMed PMID: 25328035. [PubMed: 25328035]

42. Polidori D, Mari A, Ferrannini E. Canagliflozin, a sodium glucose co-transporter 2 inhibitor, improves model-based indices of beta cell function in patients with type 2 diabetes. Diabetologia. 2014; 57(5):891-901. doi: 10.1007/s00125-014-3196-x. PubMed PMID: 24585202; PubMed Central PMCID: PMC3980039. [PubMed: 24585202]

43. Thrailkill KM, Siddhanti SR, Fowlkes JL, Quarles LD. Differentiation of MC3T3-E1 osteoblasts is associated with temporal changes in the expression of IGF-I and IGFBPs. Bone. 1995; 17(3):30713. PubMed PMID: 8541146. [PubMed: 8541146]

44. Girasole G, Passeri G, Jilka RL, Manolagas SC. Interleukin-11: a new cytokine critical for osteoclast development. The Journal of clinical investigation. 1994; 93(4):1516-24. doi: 10.1172/ 
JCI117130. PubMed PMID: 8163655; PubMed Central PMCID: PMC294166. [PubMed: 8163655]

45. Kim HN, Han L, Iyer S, de Cabo R, Zhao H, O’Brien CA, Manolagas SC, Almeida M. Sirtuin1 Suppresses Osteoclastogenesis by Deacetylating FoxOs. Molecular endocrinology. 2015; 29(10): 1498-509. doi: 10.1210/me.2015-1133. PubMed PMID: 26287518; PubMed Central PMCID: PMC4588729. [PubMed: 26287518]

46. Fowlkes JL, Bunn RC, Liu L, Wahl EC, Coleman HN, Cockrell GE, Perrien DS, Lumpkin CK Jr. Thrailkill KM. Runt-related transcription factor 2 (RUNX2) and RUNX2-related osteogenic genes are down-regulated throughout osteogenesis in type 1 diabetes mellitus. Endocrinology. 2008; 149(4):1697-704. doi: 10.1210/en.2007-1408. PubMed PMID: 18162513; PubMed Central PMCID: PMC2276714. [PubMed: 18162513] 


\section{Highlights}

- In a model of long-term hypoinsulinemic diabetes (STZ-induced hyperglycemia in DBA/2J male mice), deficits in appendicular and axial bone microarchitecture and strength are consistently observed.

- $\quad$ Normalization of glycemic control, via SGLT2-inhibitor plus insulin cotherapy, is efficacious in preventing the occurrence of diabetic bone disease in this STZ-induced model of diabetes, and glycemic status is predictive of bone phenotype.

- $\quad$ SGLT2-Inhibitor therapy alone may impart secondary effects on bone turnover.

- $\quad$ Continued surveillance of the effects of SGLT2-Inhibitors on skeletal outcomes is relevant, particularly as the clinical indications for SGLT2I therapy are expanded. 


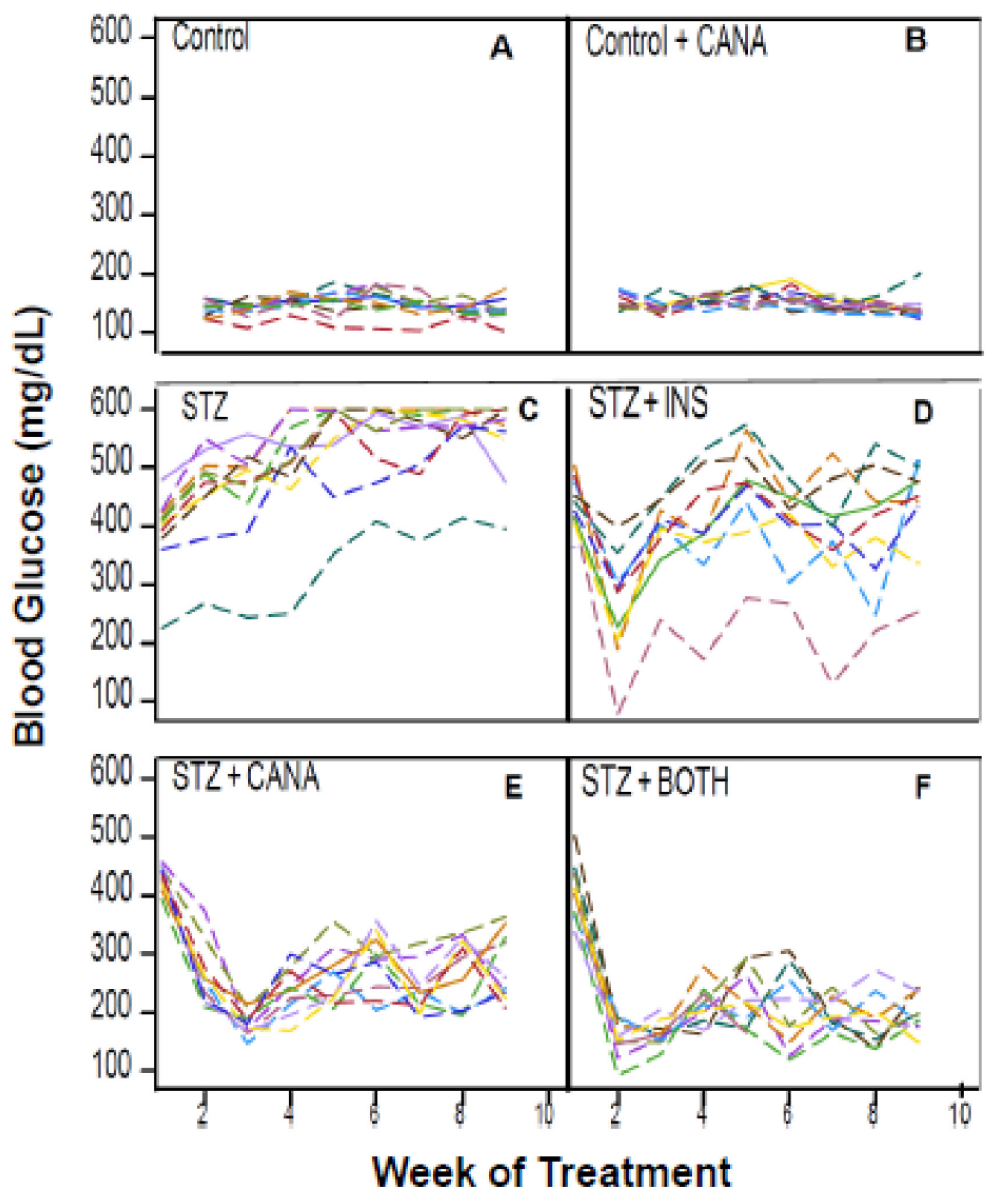

Figure 1. Blood glucose trends across treatment groups

Weekly random blood glucose (BG) measurements $(\mathrm{mg} / \mathrm{dL})$ are shown for individual animals within each treatment group from weeks 1 through 9 of treatment. 

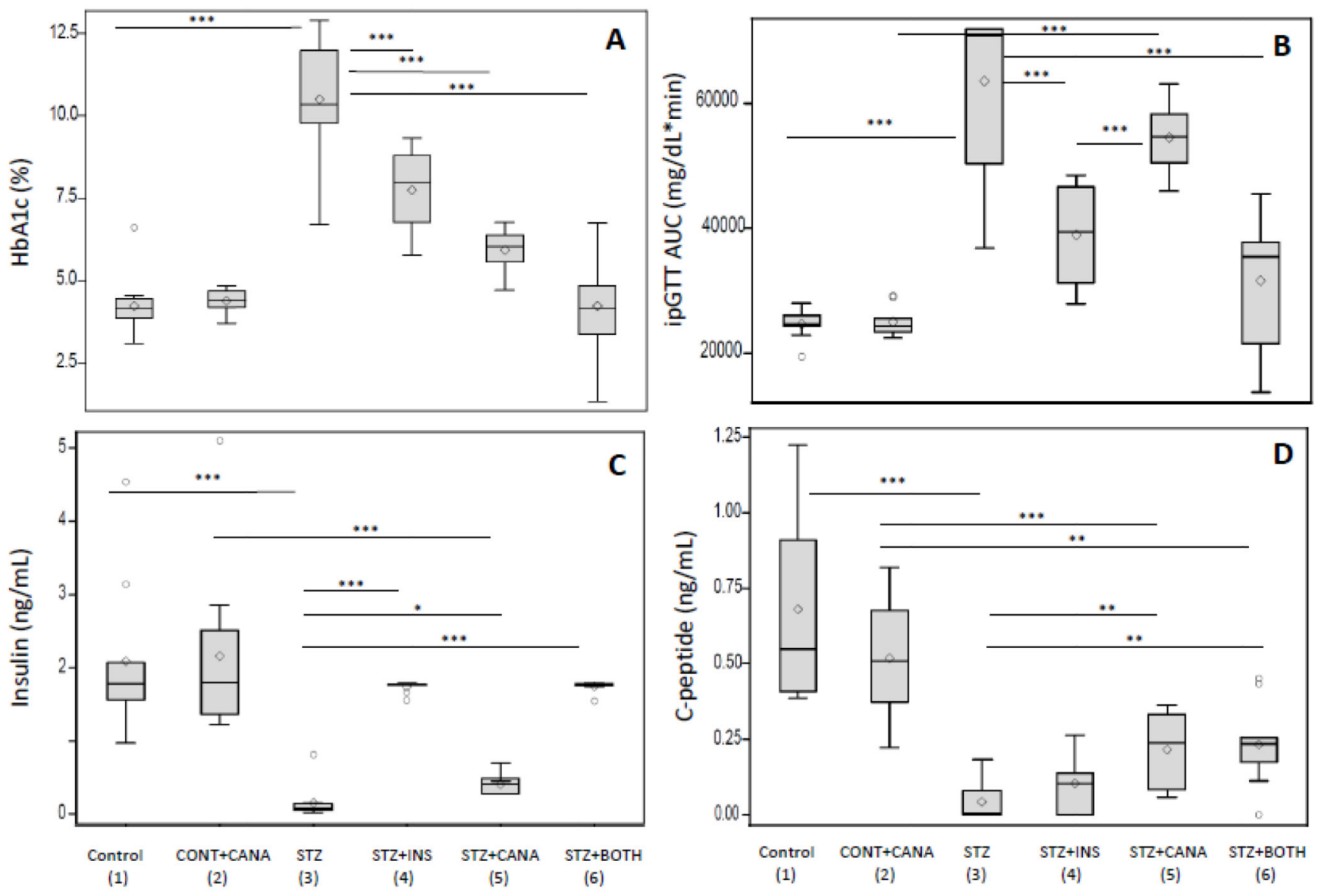

Figure 2. Metabolic parameters

A comparison of metabolic parameters across the treatment groups is shown. Parameters include: (A) HbA1c, hemoglobin A1c, \%; (B) ipGTT AUC, intraperitoneal glucose tolerance test area-under-curve, $\mathrm{mg} / \mathrm{dL} * \min$; (C) Insulin, $\mathrm{ng} / \mathrm{mL}$; and (D) C-peptide, $\mathrm{ng} / \mathrm{mL}$. $2 \mathrm{C}$ : Insulin values depicted for groups 1, 2, 3, and 5 reflect serum concentrations of endogenous mouse insulin, whereas values depicted for groups 4 and 6 reflect the serum concentration of exogenously administered human insulin. Boxplots show minimum and maximum values, interquartile range (box), median (horizontal line) and group mean (symbol). Pertinent, statistically significant differences are designated, as follows: $(*), p \leq$ $0.05 ;(* *), p \leq 0.01$; (**), $\mathrm{p} \leq 0.001$. 

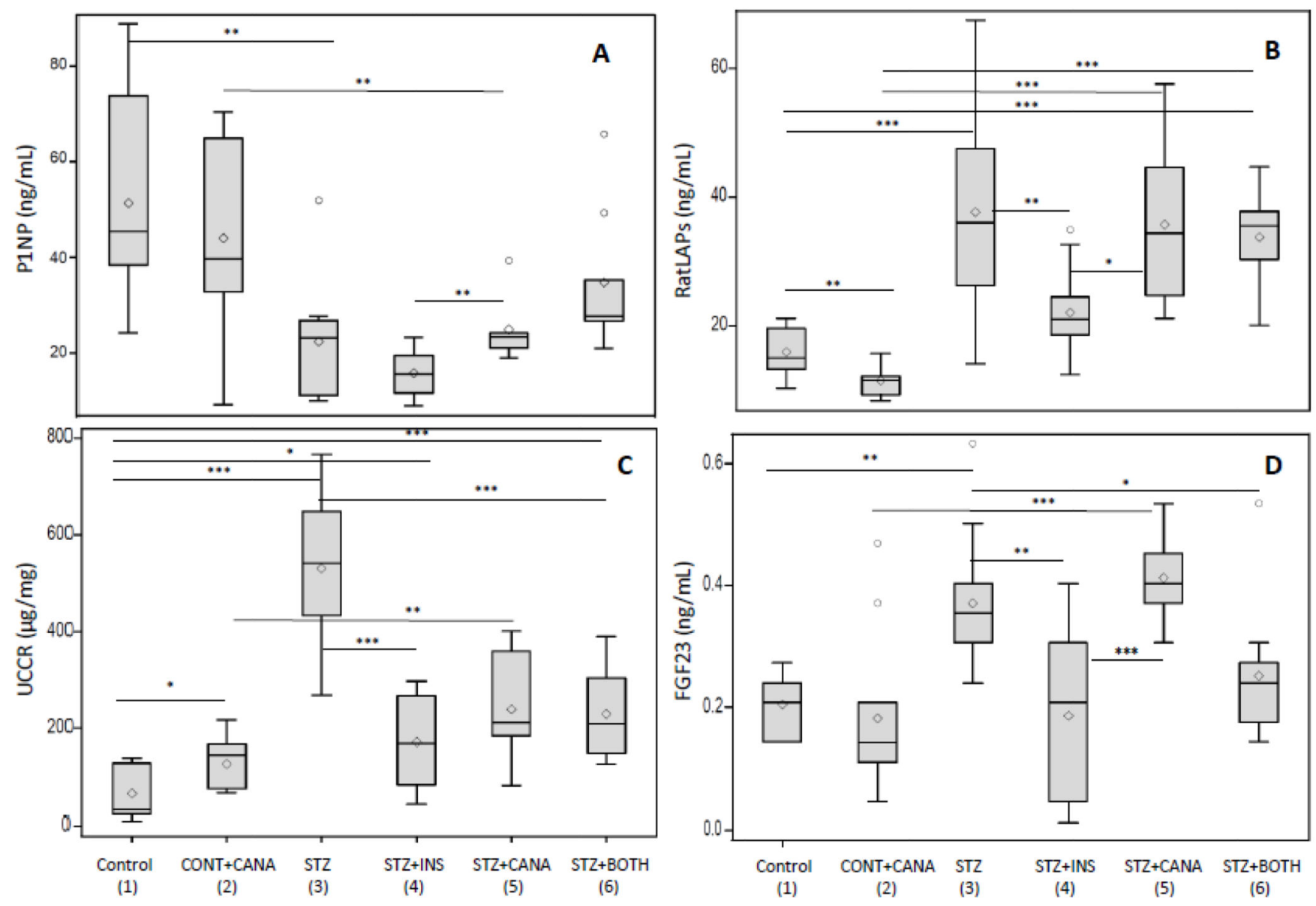

Figure 3. Bone biomarkers

A comparison of serum bone biomarker concentrations across the treatment groups is shown. Parameters include: (A) P1NP, procollagen type $1 \mathrm{~N}$-terminal propeptide, $\mathrm{ng} / \mathrm{mL}$; (B) RatLAPS, C-terminal telopeptides of type I collagen, ng/mL; (C) UCCR, urine calciumcreatinine ratio, $\mu \mathrm{g} / \mathrm{mg}$; and (D) FGF23, fibroblast growth factor-23, ng/mL. Boxplots show minimum and maximum values, interquartile range (box), median (horizontal line) and group mean (symbol). Pertinent, statistically significant differences are designated, as follows: $(*), p \leq 0.05 ;(* *), p \leq 0.01 ;(* * *), \mathrm{p} \leq 0.001$. 

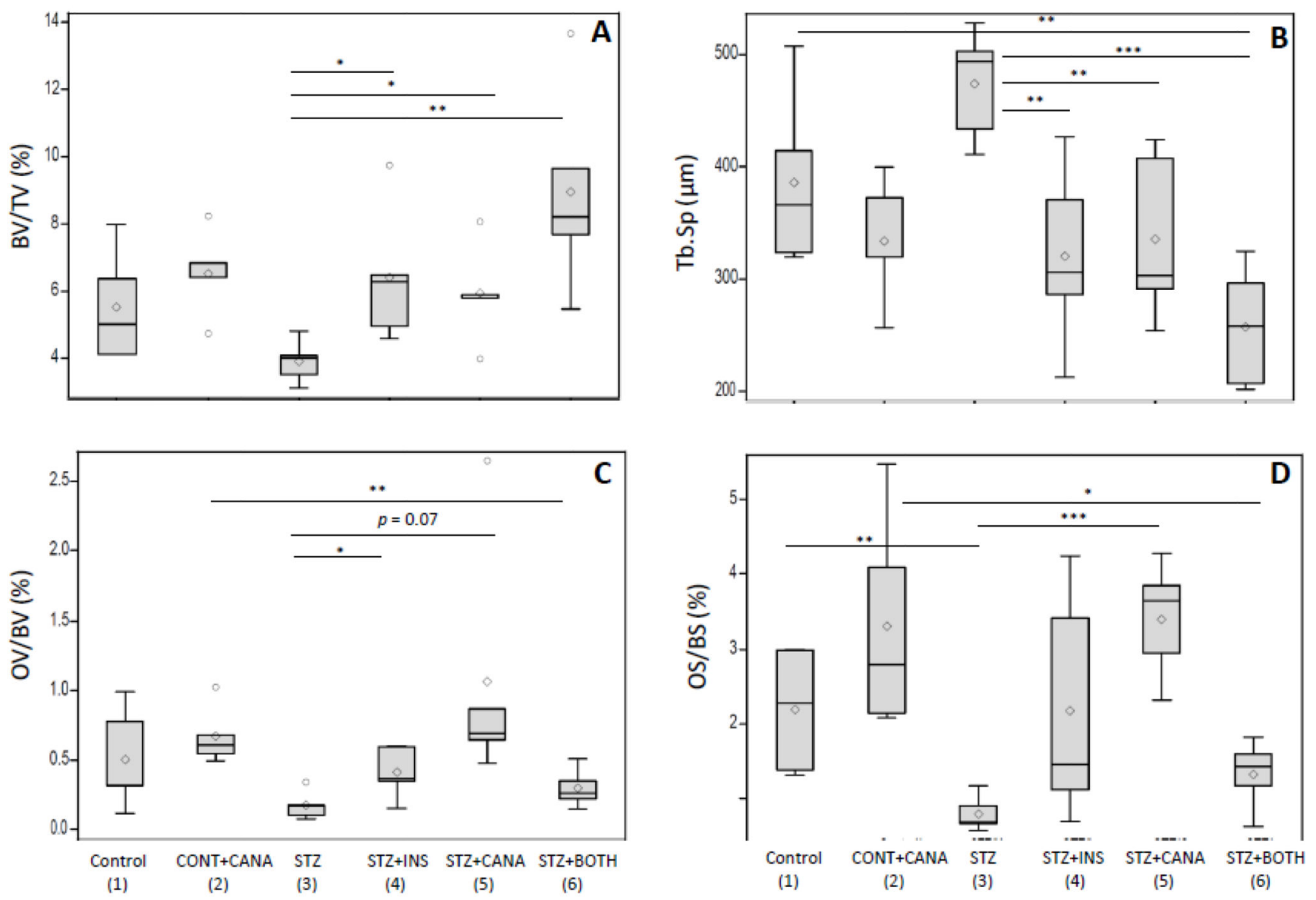

Figure 4. Histomorphometry

Selected bone histomorphometry measurements are presented, across the treatment groups.

Parameters include: (A) BV/TV, bone volume/total volume, \%; (B) Tb.Sp, Trabecular separation, $\mu \mathrm{m}$; (C) OV/BV, osteoid volume/bone volume, \%; (D) OS/BS, osteoid surface/ bone surface, $\%$. Boxplots show minimum and maximum values, interquartile range (box), median (horizontal line) and group mean (symbol). Pertinent, statistically significant differences are designated, as follows: $(*), \mathrm{p} \leq 0.05 ;(* *), \mathrm{p} \leq 0.01 ;(* * *), \mathrm{p} \leq 0.001$. 


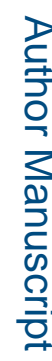

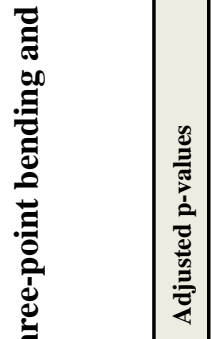

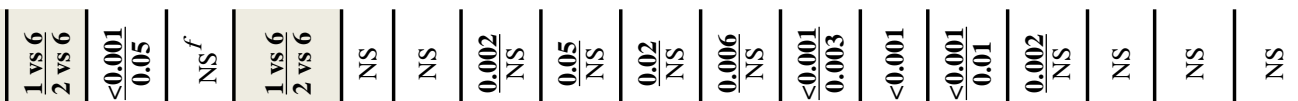

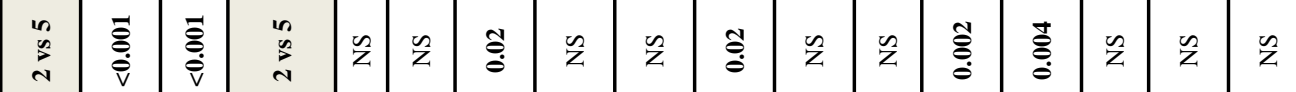

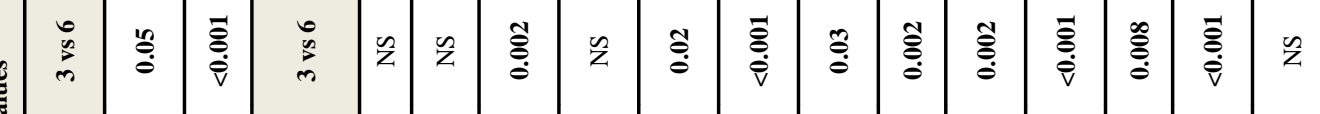

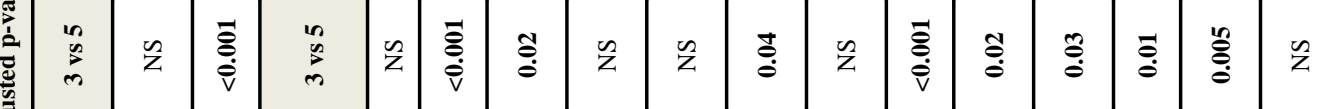

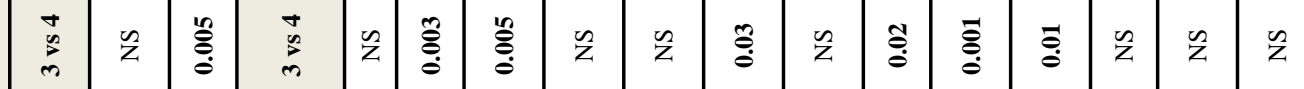

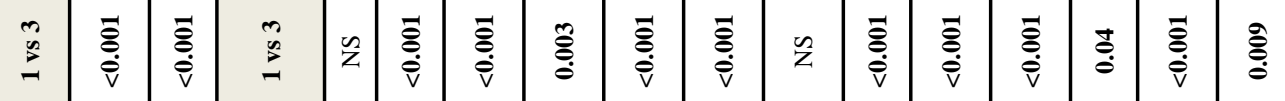

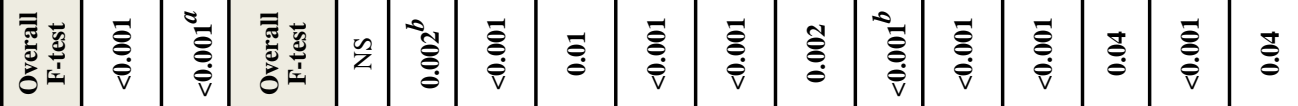

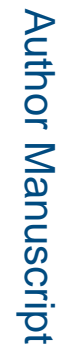

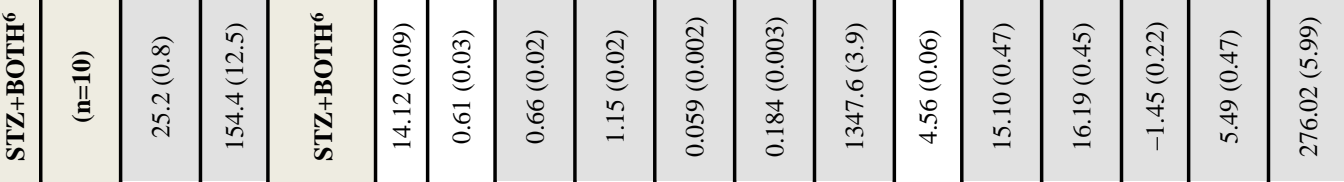

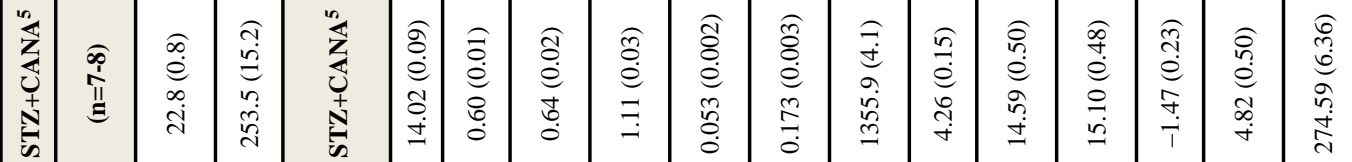
造 .

?

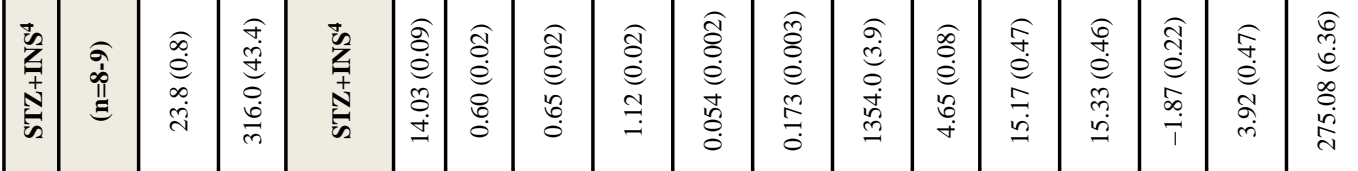

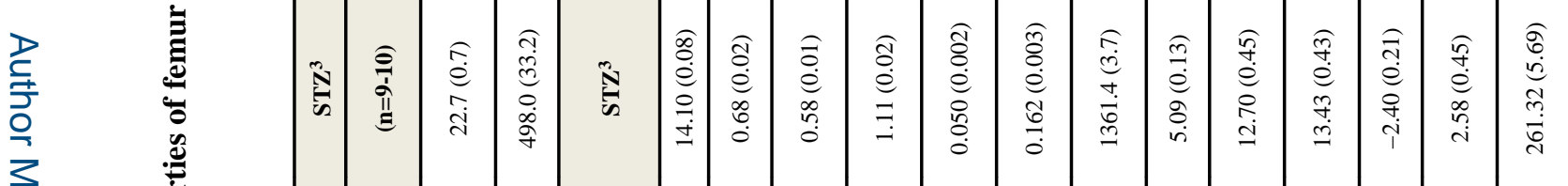
\)

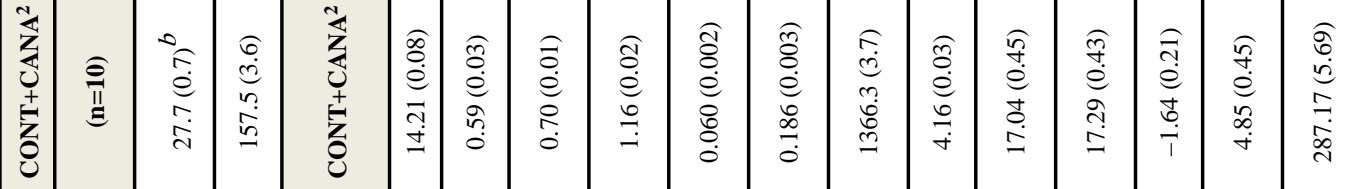

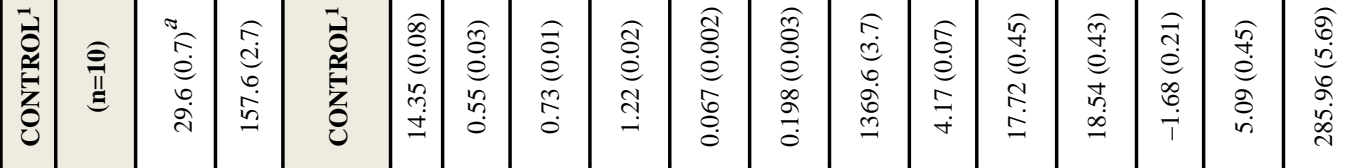

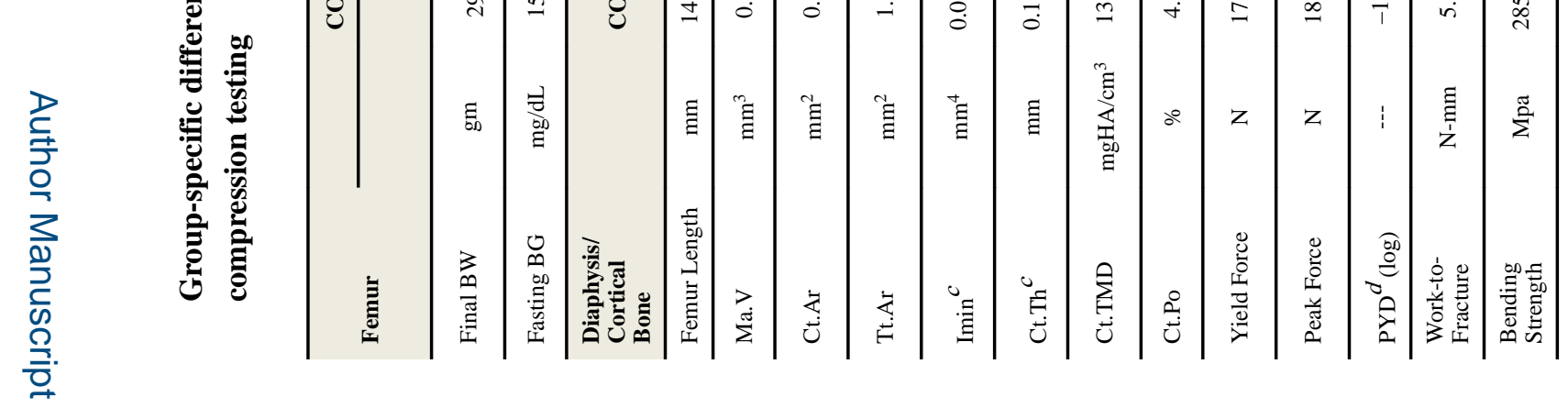
Bone. Author manuscript; available in PMC 2018 February 26. 
Thrailkill et al.

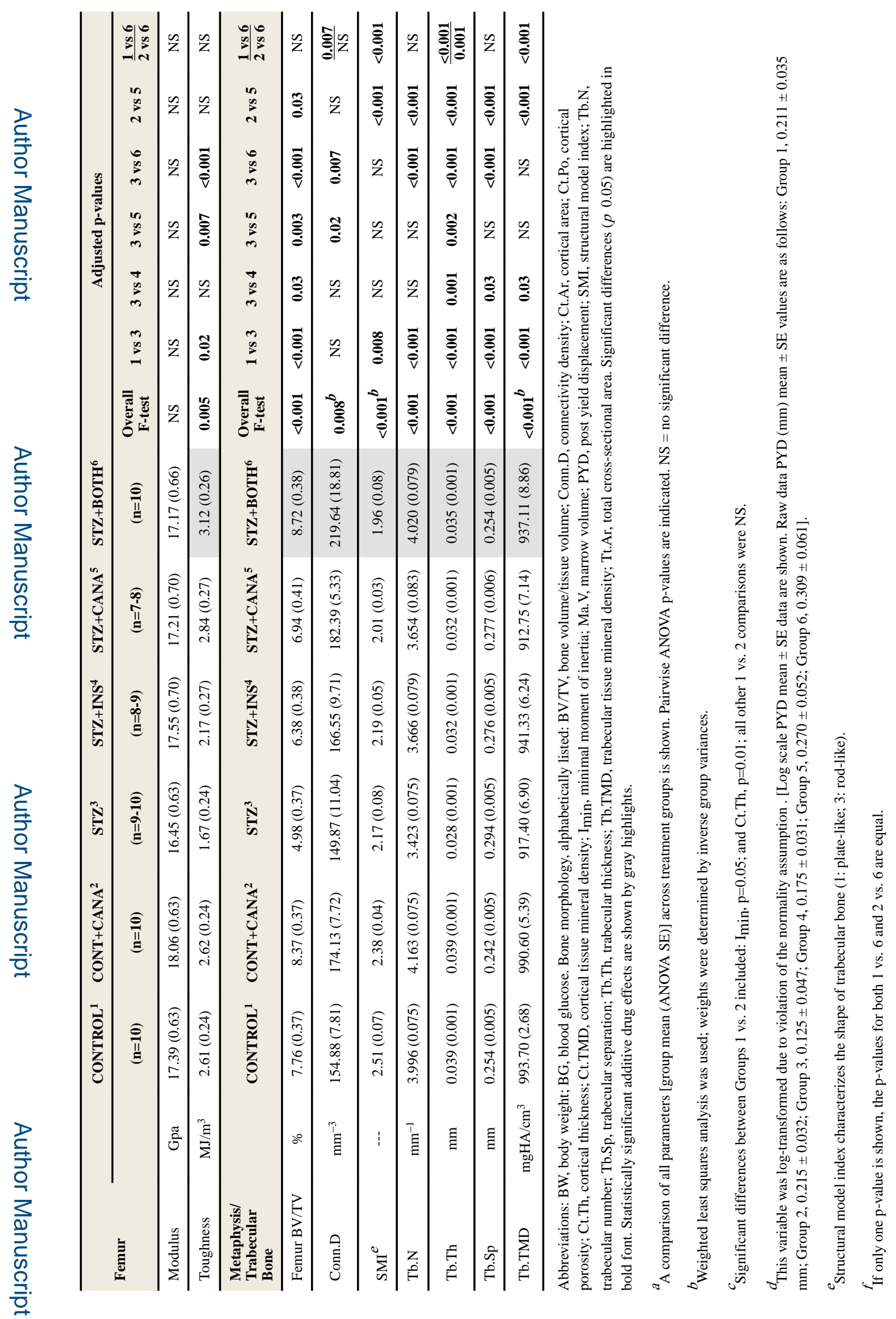

Bone. Author manuscript; available in PMC 2018 February 26. 


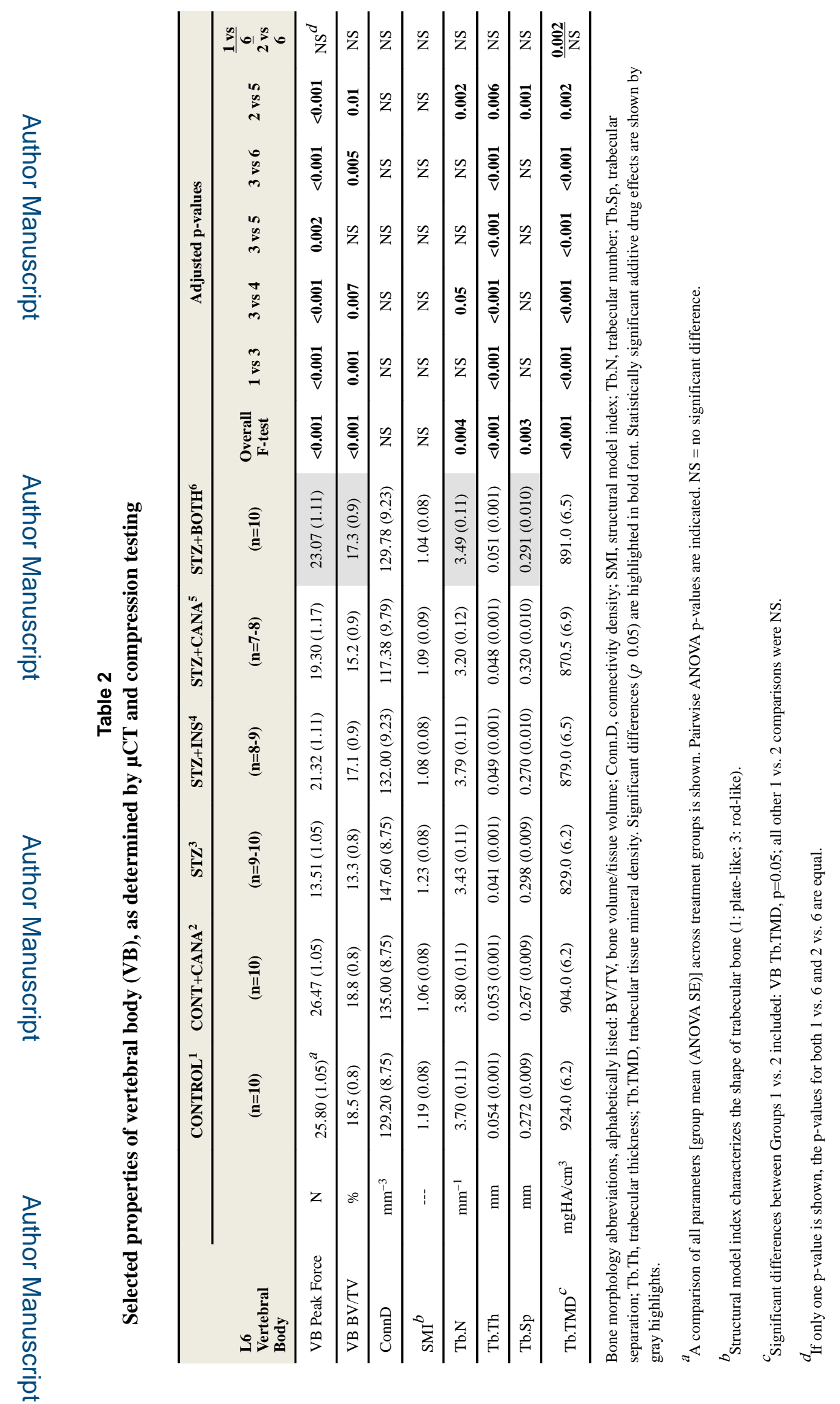

Bone. Author manuscript; available in PMC 2018 February 26. 
Table 3

The impact of glycemic status vs. bone resorption status on bone phenotype

To examine the impact of either glucose regulation or bone resorption on specific bone parameters of interest (response variables), a multiple linear regression model was fit with the following explanatory variables: treatment group, RatLAPs, UCCR, ipGTT AUC, Fasting BG, HbA1c, and body weight (averaged over the treatment period). For each of these thirteen bone parameters, at least one of these seven explanatory variables was significant ( $\mathrm{p} \unlhd$ (0.05) in predicting the outcome. Therefore, post-hoc tests (partial F-tests) were run for comparisons of interest, to test two hypotheses. In model 1, after controlling for body weight, RatLAPs and UCCR, the effect of glycemic status (treatment group, ipGTT AUC, Fasting BG, HbA1c) in predicting differences in each parameter was investigated. In model 2, after controlling for body weight, ipGTT AUC, Fasting BG, and $\mathrm{HbA1c}$, the effect of bone resorption status (treatment group, RatLAPs, UCCR) in predicting each parameter was investigated. Significant partial F-test adjusted p-values $(\$ 0.05)$ for each model are shown, to indicate whether glycemic control and/or bone resorption contributed to the outcome for each bone parameter.

\begin{tabular}{|c|c|c|c|c|c|}
\hline & $\begin{array}{c}\text { Overall F-test } \\
\text { Adjusted p-value }\end{array}$ & $\begin{array}{l}\text { Post-Hoc Test } 1 \\
\text { Glycemic Control }\end{array}$ & $\begin{array}{l}\text { Adjusted } \\
\text { p-value }\end{array}$ & $\begin{array}{c}\text { Post-Hoc Test } 2 \\
\text { Bone Resorption }\end{array}$ & $\begin{array}{c}\text { Adjusted } \\
\text { p-value }\end{array}$ \\
\hline VERTEBRAL BODY & & Predictive & & Predictive & \\
\hline Peak Force & $<0.001$ & YES & 0.004 & NO & --- \\
\hline $\mathrm{BV} / \mathrm{TV}$ & $<0.001$ & NO & -- & NO & $\begin{array}{c}-- \\
--\end{array}$ \\
\hline Tb.N & $<0.001$ & NO & $(0.06)$ & NO & --- \\
\hline Tb.Th & $<0.001$ & YES & 0.003 & YES & 0.05 \\
\hline TMD & $<0.001$ & YES & 0.002 & YES & 0.03 \\
\hline \multicolumn{6}{|l|}{ FEMUR } \\
\hline Ct.Ar & $<0.001$ & YES & 0.003 & YES & 0.003 \\
\hline Tt.Ar & $<0.001$ & NO & $(0.07)$ & YES & 0.04 \\
\hline Imin & $<0.001$ & NO & $(0.07)$ & NO & --- \\
\hline Ct.Th & $<0.001$ & YES & 0.03 & NO & --- \\
\hline Ct.TMD & 0.008 & YES & 0.05 & YES & 0.03 \\
\hline Peak Force & $<0.001$ & YES & 0.04 & NO & $(0.07)$ \\
\hline Bend Strength & $<0.001$ & YES & 0.03 & YES & 0.009 \\
\hline Toughness & 0.03 & YES & 0.05 & NO & --- \\
\hline
\end{tabular}

